University of Nebraska - Lincoln

DigitalCommons@University of Nebraska - Lincoln

PreColumbian Textile Conference VIII /

Jornadas de Textiles PreColombinos VIII (2019)

Centre for Textile Research

$6-2020$

Los "diseños verdaderos" en los tejidos de las mujeres

cashinahuá del Alto Purús

María Elena del Solar

Follow this and additional works at: https://digitalcommons.unl.edu/pctviii

Part of the Art and Materials Conservation Commons, Fiber, Textile, and Weaving Arts Commons, Indigenous Studies Commons, Latin American Languages and Societies Commons, Museum Studies Commons, and the Other History of Art, Architecture, and Archaeology Commons

This Article is brought to you for free and open access by the Centre for Textile Research at DigitalCommons@University of Nebraska - Lincoln. It has been accepted for inclusion in PreColumbian Textile Conference VIII / Jornadas de Textiles PreColombinos VIII (2019) by an authorized administrator of DigitalCommons@University of Nebraska - Lincoln. 


\title{
Los "diseños verdaderos" en los tejidos de las mujeres cashinahuá del Alto Purús
}

\author{
María Elena del Solar ${ }^{1}$
}

1. Antropóloga. Consultora independiente. Ha participado en diversos proyectos de investigación y desarrollo con organismos privados y públicos, en el ámbito de la producción textil de los Andes y la Amazonía.

\section{Resumen}

El presente trabajo constituye una aproximación a la cultura textil del grupo étnico cashinahuá con la finalidad de documentar las características particulares de los tejidos elaborados en las comunidades nativas ubicadas en los territorios de reserva del Parque nacional Purús. El arte del kené -que refiere a los diseños geométricos representados en tejidos, cestería y pintura corporal de ciertos grupos pertenecientes a la familia lingüística pano- es desarrollado específicamente en la textilería cashinahuá por mujeres especialistas, responsables de todos los niveles de decisión involucrados en la actividad y dueñas de los jardines de algodón, de donde obtienen la materia prima.

Los primeros resultados nos permiten una perspectiva bastante completa de la complejidad del pensamiento cashinahuá, expresado en la versatilidad de sus técnicas textiles - particularmente en la técnica que hemos identificado como 'varillas de memoria'- y en la singularidad de los diseños que nos remiten a la realidad cotidiana de su relación con el medio ambiente, a la vez que a los refinamientos de una estética singular.

Palabras clave: Amazonía - tradición textil cashinahuá - kené - sarga - telar con 'varillas de memoria' - diseño con simetría en espejo - geometrías simbólicas.

\begin{abstract}
This essay seeks to characterize the textile culture of the Cashinahuá ethnic group in order to document the particular characteristics of the textiles created by native communities living on reserved territories within the Purús National Park. The art of kené -which refers to the geometric designs represented in textiles, basketry and body painting of certain groups belonging to the Pano linguistic family- is specifically developed in Cashinahuá textiles by women who are specialists, responsible for every level of decision-making involved in this activity and owners of the cotton gardens from which the raw material is obtained.

These initial research results provide quite a complete vision of the complexity of Cashinahuá thought, expressed in the versatility of their textile techniques - particularly in the technique that we have identified as 'memory sticks'- and in the singularity of patterns that reference the day to day reality of their relationship with the environment, and at the same time their refined and singular aesthetic.

Key words: Amazon Basin -Cashinahuá textile tradition - kené - twill - loom with 'memory sticks' - design with mirror symmetry - symbolic geometries.

\section{Resumé}

Le présent article propose une première approche de la culture textile du groupe cashinahuá. Il a pour objectif de documenter les caractéristiques particulières des tissus réalisés dans les communautés localisées sur le territoire de la réserve du Parc national Purús. L’art du kené - terme qui se réfère aux dessins géométriques présents sur les tissus, la vannerie et les peintures corporelles de certains groupes de la famille linguistique pano - apparaît tout spécialement dans la production
\end{abstract}

DOI: $10.32873 /$ unl.dc.zea.1222

Published in PreColumbian Textile Conference VIII / Jornadas de Textiles PreColombinos VIII, ed. Lena Bjerregaard and Ann Peters

(Lincoln, NE: Zea Books, 2020). https://digitalcommons.unl.edu/zeabook/ 
textile de tisserandes spécialisées, responsables de toutes les décisions prises dans le déroulement de cette activité et, en même temps, propriétaires des jardins de coton d'où elles tirent la matière première pour cette activité.

Les premiers résultats offrent une perspective assez complète de la complexité du mode de pensée des cashinahuá tel qu'il s'exprime dans la façon de tisser, dans la versatilité des techniques et dans la singularité des dessins. Tous ces éléments témoignent de la réalité quotidienne de leur relation avec leur environnement, en même temps que des aspects raffinés de leur esthétique.

Mots clés: Amazonie - tradition textile cashinahuá - kené - sergé - métier à tisser avec 'baguettes de mémoire’ - dessin avec symétrie en miroir - géométries symboliques.

\section{Contextos}

El pueblo cashinahuá se encuentra ubicado hacia el sud este de la Amazonía peruana, en los territorios de la Reserva Comunal del Parque Nacional Purús, en la provincia de Purús, departamento de Ucayali, con una población aproximada de entre 2,500 y 3,00o habitantes asentados en las riberas de los ríos Curanja y Alto Purús. (Lámina 1) Un sector importante de la misma familia étnica vive en Brasil, en las riberas de los ríos Alto Embira y tributarios, en el estado de Acre, constituyendo una mayor concentración de población que la que se encuentra en territorio peruano. Ambos sectores se encuentran comunicados por vía fluvial, mantienen relaciones de parentesco y se suelen reunir en ocasión de festividades.

Los cashinahuá pertenecen a la familia lingüística pano y constituyen el grupo de población más numeroso que habita en la Reserva comunal del Purús, en relación a los yaminahua, sharanahua, mastanahua y culina. El término cashinahuá se traduce como "gente murciélago" y aunque se trata de una denominación formal, de uso oficial, la misma población se reconoce entre sí con el apelativo huni kuin, que significa 'gente verdadera', y es la voz que suelen emplear al hacer referencia directa y coloquial.

Los cashinahuá habitaron tradicionalmente en una amplia área interfluvial conformada por las nacientes de los ríos Purús y Yurúa. Hacia fines del XIX, tiene lugar la fiebre del caucho, que tuvo su auge entre 1879 y 1912, experimentando, tiempo después, un renacimiento entre los años de 1942 y 1945, con la segunda guerra mundial. La población conserva en la memoria colectiva los sufrimientos y abusos cometidos por empresarios brasileros y peruanos en aquellos tiempos, donde fueron sometidos a condición de explotación, de esclavitud, de epidemias y de desplazamientos forzados, en territorio brasilero y peruano, que trajeron como consecuencia una fuerte baja demográfica. Más adelante, el contacto con habilitadores de madera, shiringueiros y compradores de pieles de animales silvestres con la finalidad de obtener herramientas, ropa y alimentos trajo nuevos

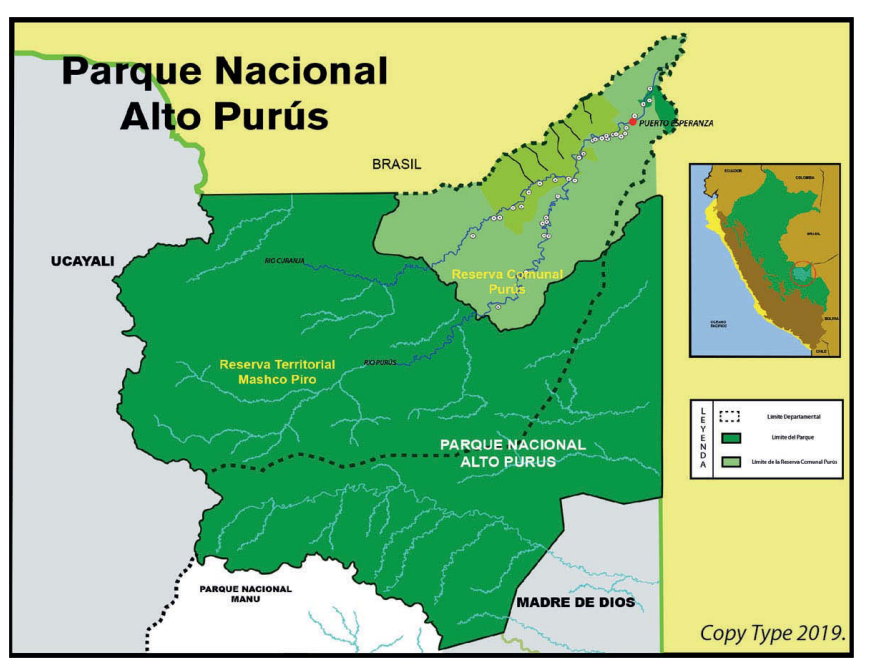

brotes epidémicos que diezmaron la población adulta desapareciendo cerca de un $75 \%$ de sus habitantes.

Los cambios en los patrones de asentamiento y la adaptación al hábitat ribereño se estabilizaron aproximadamente a partir de la década de 1970, aunque persisten a la fecha nuevas movilizaciones y la fundación de nuevas comunidades, motivados mayormente por la necesidad de encontrar espacios con mayores recursos de caza y también para acercarse al centro poblado de Puerto Esperanza, con acceso a servicios de salud, a bienes de comercio y de subsidios sociales. ${ }^{2}$

Las comunidades cashinahuá comparten una serie de rasgos culturales como, la organización social basada en mitades que ordenan la filiación de los individuos, el sistema de nombres, la selección de la pareja, la transmisión de conocimientos, así como las ceremonias y el universo ritual. Las mitades tienen una estructura exogámica y patrilineal, esto es, cada uno de los miembros de la pareja debe de pertenecer a una mitad, Inubake y Duabake (jaguar y luz radiante respectivamente). El lugar de residencia de una nueva pareja es la casa de los padres de la esposa, estableciendo un patrón uxorilocal. Son muy apreciados los conocimientos herbolarios y diversas técnicas terapéuticas. 


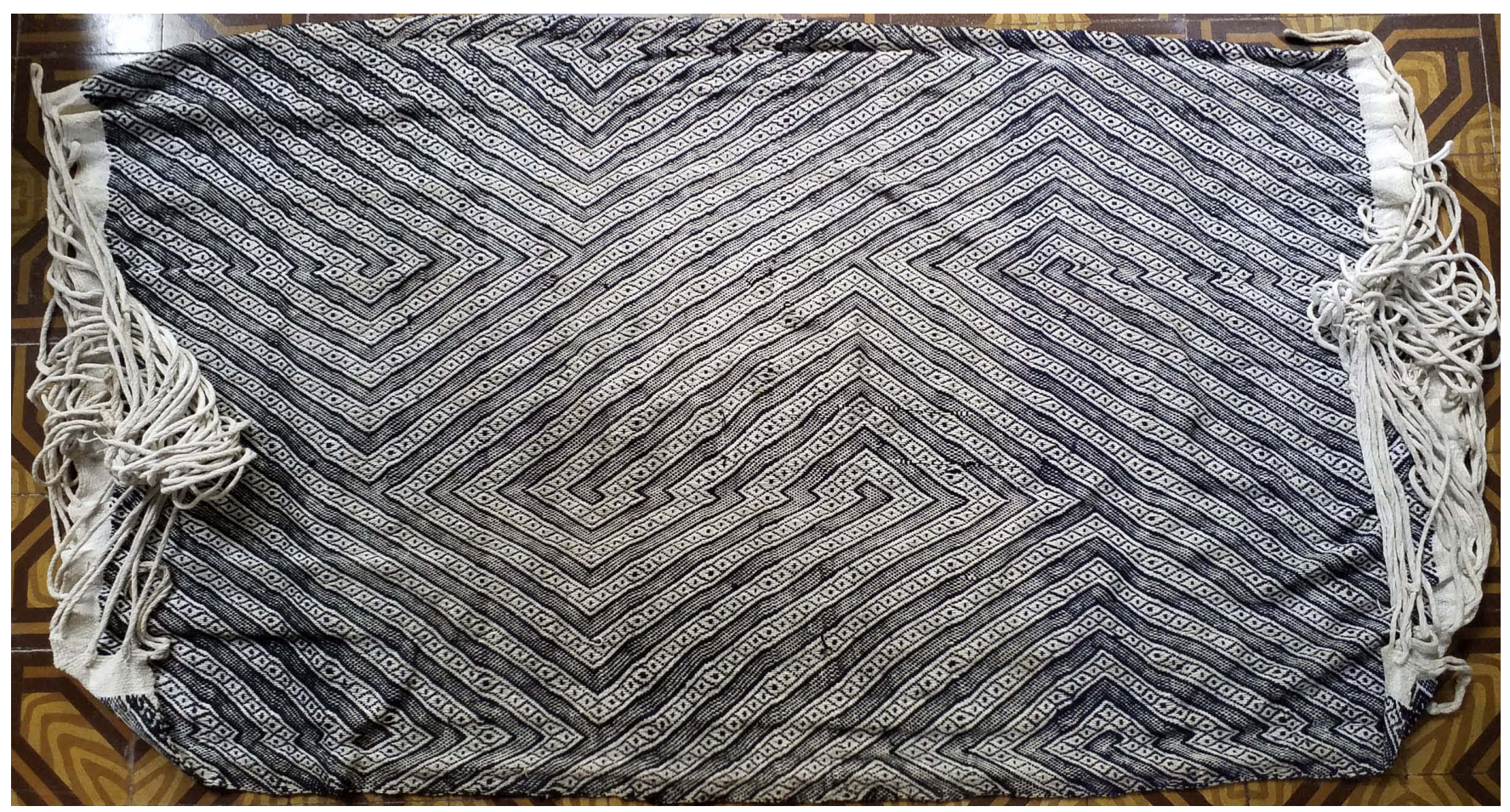

Foto 1 Hamaca de un solo paño. Hilda Pinedo, CCNN Colombiana. Foto: M.E. del Solar

Hoy en día, la caza de aves y carne de monte, a cargo de los hombres, es la principal fuente para el sostenimiento de las familias, aunque las actividades de pesca y la producción de yuca, maní y frutales (plátano, papaya, pacae) en las chacras a cargo de las mujeres, complementan una ingesta de alimentos equilibrada.

\section{Los tejidos cashinahuá}

Vengan hermanas, acérquense, vamos a aprender, vamos a observar, el diseño de la mantona.

Mirar nos dará inteligencia y sabiduría.

$Y$ cuando estemos juntas no se muevan, todas quietas como loro.

Porque el loro, cuando escucha aprende rápido.

No se muevan, no hagan bulla, como el loro se está quieto para aprender. ${ }^{3}$

La importancia del tejido en la sociedad cashinahuá es evidente si se consideran los múltiples espacios en los que mantiene una presencia importante como marcador de identidad. Es parte fundamental del espacio doméstico, pocas casas familiares visitadas no cuentan con un telar instalado o con una tejedora en plena actividad. La producción de textiles en las comunidades es fundamentalmente una tarea femenina y mantiene un fuerte carácter etnográfico; la calidad y complejidad de sus técnicas y diseños destaca especialmente frente a expresiones de la cultura material de otros pueblos de la región. ${ }^{4}$ (Foto 1 )

El vestido tradicional cashinahuá ha desaparecido hoy de la vida cotidiana, se viste exclusivamente en ceremonias festivas tradicionales, maridi hatxamawa, para la cosecha de productos de la chacra (plátano, yuca, maíz), y en general para toda ceremonia referida a la fertilidad, a la multiplicación -de la tierra, de los hombres, de las cosas- o en los rituales de iniciación. Una parte de la producción textil se destina a la comercialización en la ciudad brasileña cercana de Santa Rosa, sobre el mismo río Purús, punto de referencia social y comercial de los cashinahuá y de mestizos peruanos. Otra pequeña parte se comercializa con el apoyo de las hermanas evangélicas que visitan las comunidades.

3. Canción propiciadora del aprendizaje del tejido cantada por la tejedora Sandra Pinedo, 26 años. CCNN Colombiana 2019. Traducción: Jacob Torres, huni kuin. Guardaparque de la Reserva Comunal Purús. Servicio Nacional de Áreas Naturales Protegidas, SERNANP.

4. Los estudios etnográficos de Kensinger (1975) constituyeron una fuente de información relevante para la colección representativa de tejidos, plumarios y otros artefactos de la cultura material cashinahuá que fueron adquiridos, en las décadas de 1960-70, por el mismo Kensinger, para la colección Haffenreffer, hoy en la Universidad de Brown, en los EEUU, así como para Temple University, Pennsylvania Museum, Musée du Quai Branly, posiblemente entre otros. 
Presentamos una relación de las diversas prendas del vestido tradicional cashinahuá: (Tabla 1)

\begin{tabular}{|l|l|l|}
\hline \multicolumn{2}{|c|}{$\begin{array}{c}\text { Los tejidos de algodón } \\
\text { Xapu tima }\end{array}$} \\
\hline En telar de cintura & Kapanka / kapu & $\begin{array}{l}\text { Empleado para portar implementos de caza por } \\
\text { los hombres. }\end{array}$ \\
\hline Morral & Tadi hidabi & Túnica de hombre. \\
\hline Cushma & Txinexeti xampana & Empleada por los hombres en ceremonias. \\
\hline Falda & Tudu tadi & Antiguamente cubría hasta las rodillas. . \\
\hline Chaleco hombre & $\begin{array}{l}\text { Yumen huxe } \\
\text { puxti }\end{array}$ & $\begin{array}{l}\text { Sujetan las junturas alrededor de muñecas, bra- } \\
\text { zos, tobillos y debajo de las rodillas. }\end{array}$ \\
\hline Brazaletes & mabi & Para decorar los brazos en las fiestas. \\
\hline Muñequera & Yumen hash kanti & $\begin{array}{l}\text { Se porta cruzada en diagonal sobre el pecho, tanto } \\
\text { hombres como mujeres. }\end{array}$ \\
\hline Banda & Pampana & Indistintamente para hombres y mujeres. \\
\hline Cinturón & Maxti & $\begin{array}{l}\text { Plumas y banda en algodón sobre estructura de } \\
\text { caña }\end{array}$ \\
\hline Corona & $\begin{array}{l}\text { Plumas y banda en algodón sobre estructura de } \\
\text { caña }\end{array}$ \\
\hline Corona mujer & Yumen maiti & $\begin{array}{l}\text { De uno o dos paños, para dormir o para descansar } \\
\text { durante el día. }\end{array}$ \\
\hline En telar diagonal & Tanka, turukare & Para abrigo. Se tejen poco en la actualidad. \\
\hline Hamacas & Disi tima & Patrón tubular \\
\hline Mantas & \multicolumn{2}{|l|}{} \\
\hline En telar de urdimbres contínuas &
\end{tabular}

Si bien no es parte de la vestimenta cotidiana, se acostumbra preparar con cuidado los atuendos y complementos que serán vestidos durante festividades y ceremonias. El ingreso económico por su comercialización es eventual y precario pero constituye una posibilidad de dinero para adquirir ciertos bienes de consumo que no producen en la chacra (ropa, alimentos, medicinas).

La riqueza del vocabulario textil constituye un argumento importante para valorar la vigencia de la actividad del tejido -su cualidad, textura, apariencia- fuertemente ensamblado al sistema de pensamiento ritual y a los aspectos formales de la identidad cashinahuá.

\section{Tipos de telares, descripción y funcionalidad}

Las tejedoras cashinahuá emplean el telar tradicional como herramienta básica para la producción de tejidos de algodón, común a diversos pueblos de la región amazónica, tanto de las familias pano como arawak y jíbaro.

Se han identificado tres variantes del telar tradicional, adecuados funcionalmente al tipo de prenda que se teje, especialmente en cuanto a las dimensiones de la pieza se refiere. Primero, se observan dos variantes que producen tejidos con cuatro orillos. Uno tiene la tensión de la urdimbre ejercitada por el cuerpo de la tejedora. Es el telar de cintura usado para tejer morrales, camisas y túnicas, y prendas de menor tamaño como bandas de pecho y coronas o vinchas, que servirán, estas últimas, como base para los tocados de plumas. Este telar no tiene lizos, los hilos se escogen manualmente en cada cruce de la trama, pero tiene la particularidad del empleo de finas varillas para memorizar en la zona superior de la urdimbre los hilos escogidos que componen el diseño en la zona inferior. Esas varillas permiten reproducir 'en espejo' el mismo diseño sin tener que escoger los hilos y, de esta manera, se logra una importante economía en el tiempo y esfuerzo invertidos.

La segunda variante tiene una tensión estable para sustentar una urdimbre de dimensión mucho mayor. Es el telar diagonal empleado para la confección de paños para las hamacas, y en décadas pasadas para la confección de mantas destinadas a ceremonias y para abrigo. ${ }^{5}$ En el caso de que no se trabajen diseños, o parcialmente combinados con franjas de tela llana, el telar puede tener un lizo y un separador. Cuando hay un diseño escogido que se repite en la urdimbre 'en espejo' (no siempre es el caso), la tejedora puede usar varillas para memorizar los hilos escogidos en la parte superior 
de la urdimbre, mientras se compone el diseño en la zona inferior. ${ }^{6} \mathrm{Si}$ el empleo de varillas parece común en el telar de cintura, es de uso menos regular en el telar diagonal.

La tercera variante, el telar de urdimbre continua, se caracteriza por el urdido de una urdimbre circular necesaria para producir las faldas tubulares que llevan las mujeres.

- Telar de cintura.- Es la técnica más difundida y consiste en un sistema de barras, anterior y superior, sobre las que se montan los hilos que van a formar el urdido. La trama, como elemento activo, complementa la estructura del tejido, y la técnica de entrecruzamiento de los ligamentos definirá el diseño. No se emplea el lizo, mas sí es frecuente el empleo de las varillas que replican la selección de las urdimbres en espejo, hacia el extremo superior del tejido. Una faja a la cintura, de allí el nombre del telar, enganchada a ambos extremos de la barra anterior, permite a la tejedora tensar o soltar a voluntad las urdimbres, con el peso de su cuerpo, para permitir pasar la trama a través del espacio de la calada. La barra superior del telar se suele amarrar a alguna saliente de las paredes de la vivienda. (Foto 2)

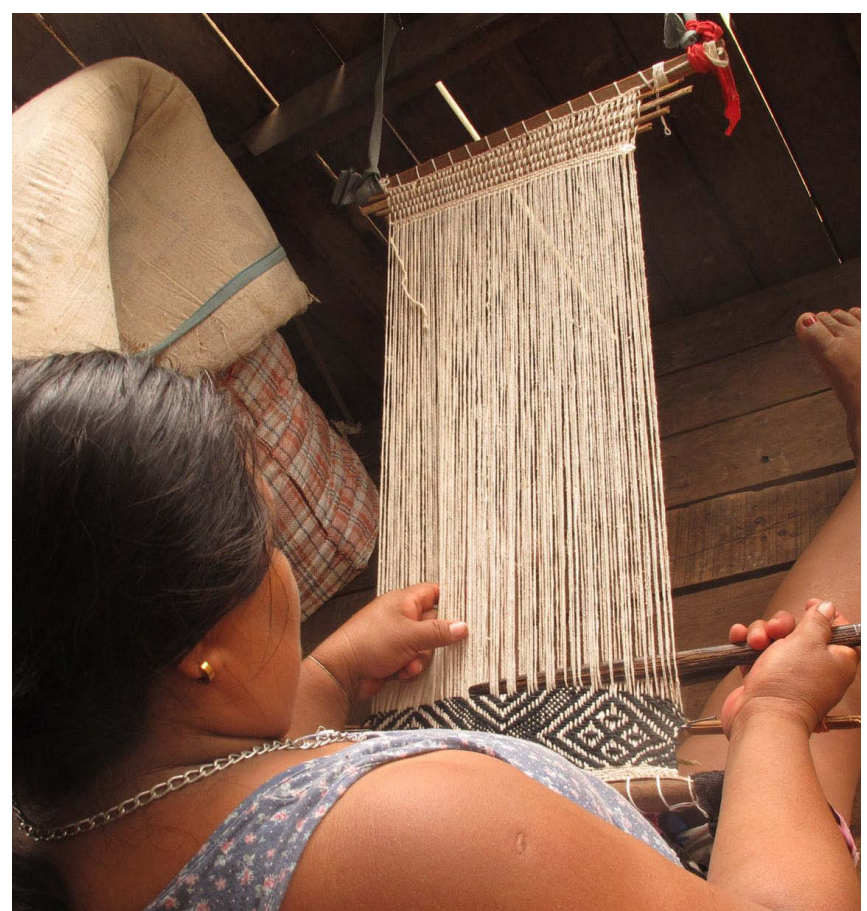

Foto 2 Doris Salomón escogiendo las urdimbres para confección de un morral en telar de cintura. CCNN de San Martín 2018. Foto: M.E. del Solar

-Telar diagonal.- Este telar se asegura, o se cuelga, en el centro de la vivienda, a una viga especialmente acondicionada, y se fija directamente al piso para quedar inmovilizado. Los tejidos desarrollados en este tipo de telar diagonal pueden alcanzar un ancho máximo de $1.25 \mathrm{~m}$. lo que requiere de una especial pericia de la tejedora, que puede optar por la técnica de escogido en todo el paño, por el armado de lizos o por el empleo de varillas para guardar la memoria del diseño. En estos telares, se mantiene la estructura de cuatro orillos para la confección de hamacas; estas pueden ser de un paño para usar durante el día o de dos paños, cosidos longitudinalmente, para lograr un mayor ancho y mayor comodidad para el descanso. (Foto 3)

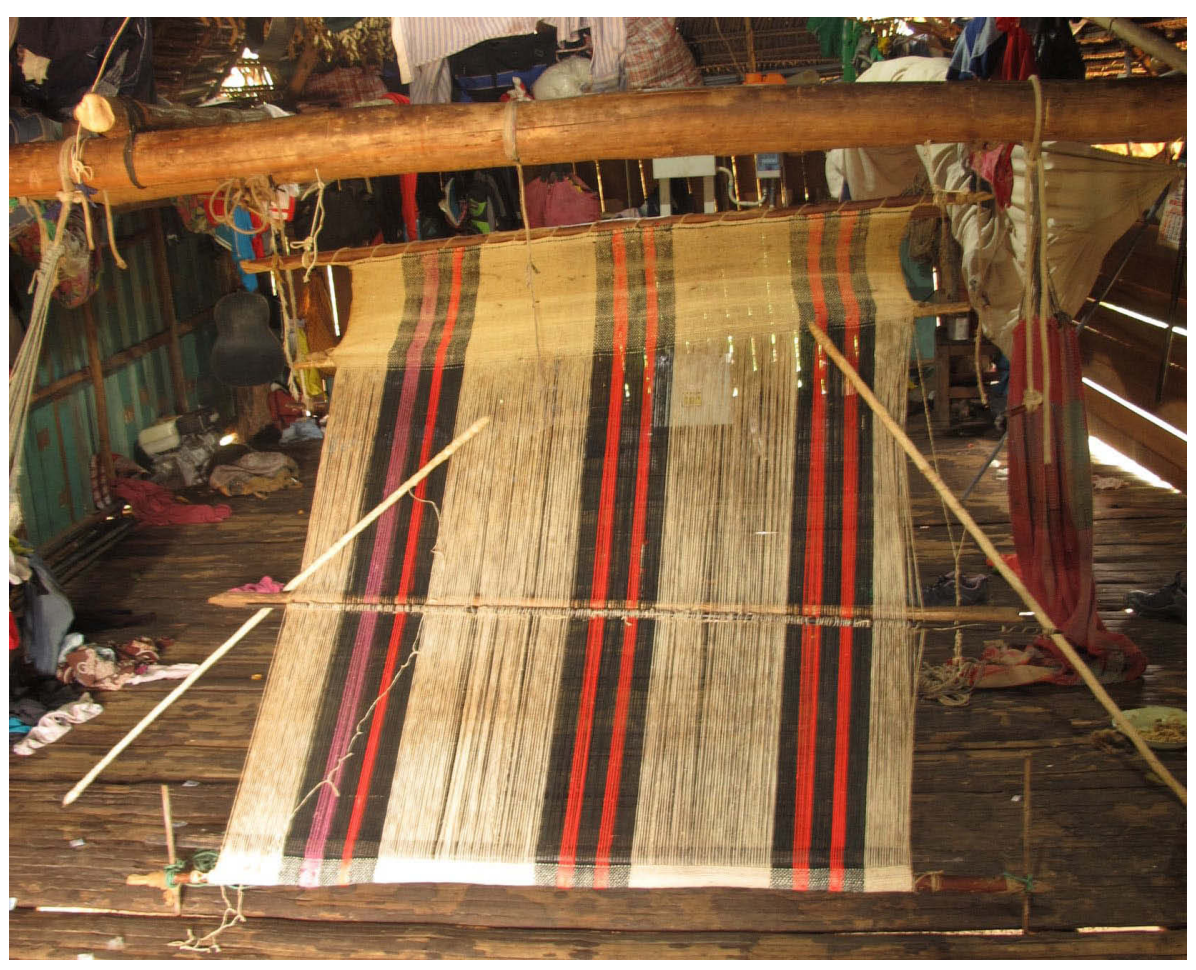

Foto 3 Telar diagonal para tejer hamacas. Elena López Nacimiento, CCNN San Martín 2018. Foto: M.E. del Solar 
-Telar de urdimbre continua.- Consiste en un telar horizontal cuyas barras delantera y posterior se sujetan con cuerdas a cuatro estacas que se plantan en el suelo. La construcción del diseño implica la manipulación de las urdimbres con la ayuda del escogedor, yume tupikin, excluyéndose, en este caso, el empleo de lizos o varillas para guardar la memoria del diseño, como se ha señalado en los casos anteriores. El producto final será un tejido de patrón tubular, empleado especialmente en la confección de faldas. Es la única prenda tejida en donde las urdimbres, en la vestimenta, pasan a la posición horizontal. ${ }^{7}$ (Foto 4)

\section{Técnicas tradicionales de elaboración de tejidos}

\section{Los recursos del bosque:}

El algodón nativo es el principal recurso para el tejido. La variedad identificada, gossypium barbadense, es originaria de América del sur y de amplia distribución en poblaciones silvestres en climas tropicales. Es muy apreciado por su fibra larga, suavidad y brillo, así como por su resistencia a las plagas.

Es cultivado en pequeña escala en las chacras cercanas a la vivienda y cuidado por las mujeres cashinahuá, donde se identifica un indudable servicio ambiental ya que su manejo a través del arte textil tradicional contribuye a la preservación de las variedades nativas, por tanto a la conservación in situ del material genético del Parque. Su característico tono crema se emplea en combinación con el negro o azulgrisáceo oscuro para obtener el contraste definido que mejor destaca los diseños. El algodón de color pardo se emplea en menor cantidad. La huerta familiar, a cargo de la mujer, provee de especies tintóreas, entre las más difundidas están el huito (Genipa americana) de donde se obtiene el color azul grisáceo oscuro y el negro, que también se emplea en la pintura corporal; las semillas de achiote (Bixa orellana), maxe, para el rojo y anaranjado oscuro; el palillo (Curcuma longa), raíz comestible de la que se obtienen varios tonos de amarillo y ocre.

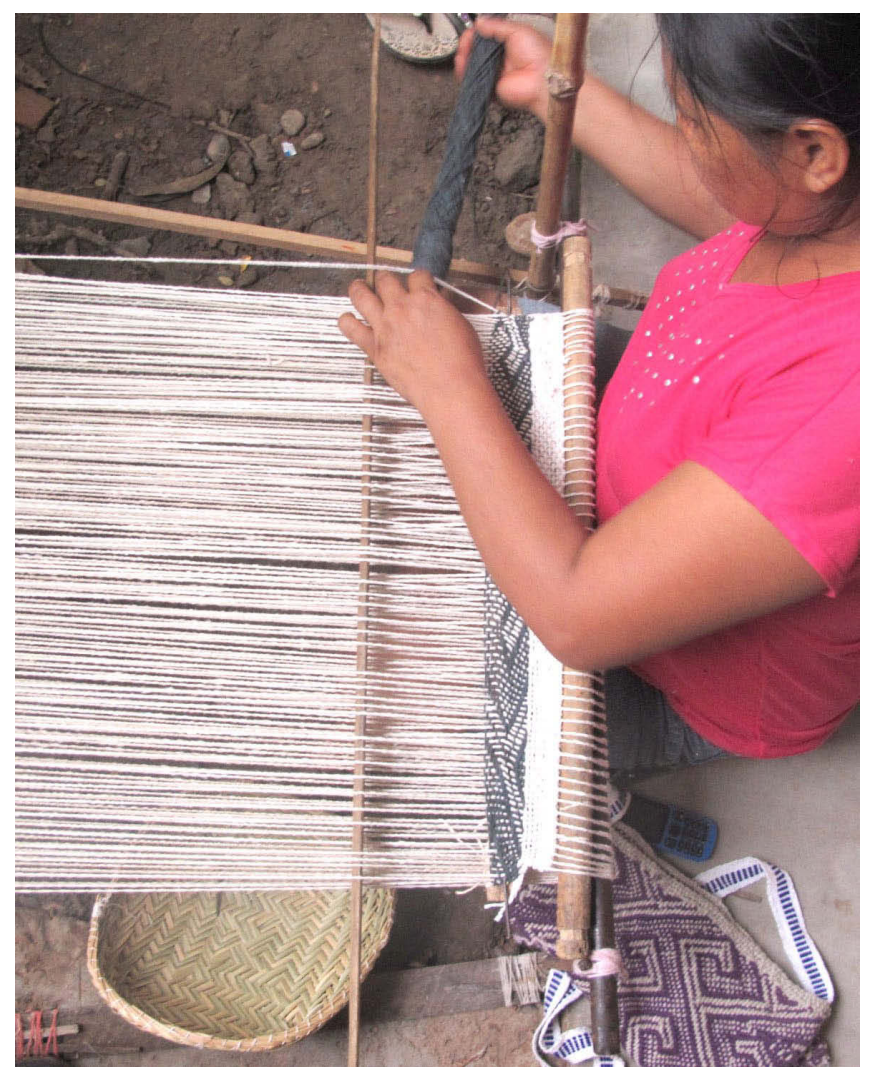

Foto 4 Florinda Torres Montes, iniciando el tejido de una falda en telar de urdimbre contínua. CCNN Conta 2018. Foto: M.E. del Solar

Las incursiones más profundas al bosque suelen estar a cargo de los varones de la familia donde se combina la caza con la cosecha de semillas diversas para la confección de adornos para la decoración personal y/o la venta menuda; también para la extracción de trozos de corteza de caoba (Swetenia macrophylla), ischinanti, o palos de árboles u hojas conocidos, de donde se obtienen otros colores como rosa, azul, morado o verde. Estos colores suelen aparecer como fondo en paneles alternados, especialmente en las hamacas, sobre los que va a destacar con mayor intensidad el diseño construido en el contraste claro-oscuro.

\begin{tabular}{|l|l|l|}
\hline \multicolumn{1}{|c|}{ Tono de algodón } & \multicolumn{1}{c|}{ Nombre cashinahuá } & \multicolumn{1}{c|}{ Nombre científico } \\
\hline Blanco marfil & xapu jushipa & Gossypium barbadense \\
\hline Marrón (más obscuro) & xapu junishipa / jushinepa & Gossypium barbadense \\
\hline Marrón (más claro) & xapu kurupá & Gossypium barbadense \\
\hline
\end{tabular}

7. La estructura de las cushmas ashaninka, túnica femenina, lleva igualmente las urdimbres horizontales en dos paños unidos horizontalmente. Para ampliar información ver: Desrosiers 1992. 


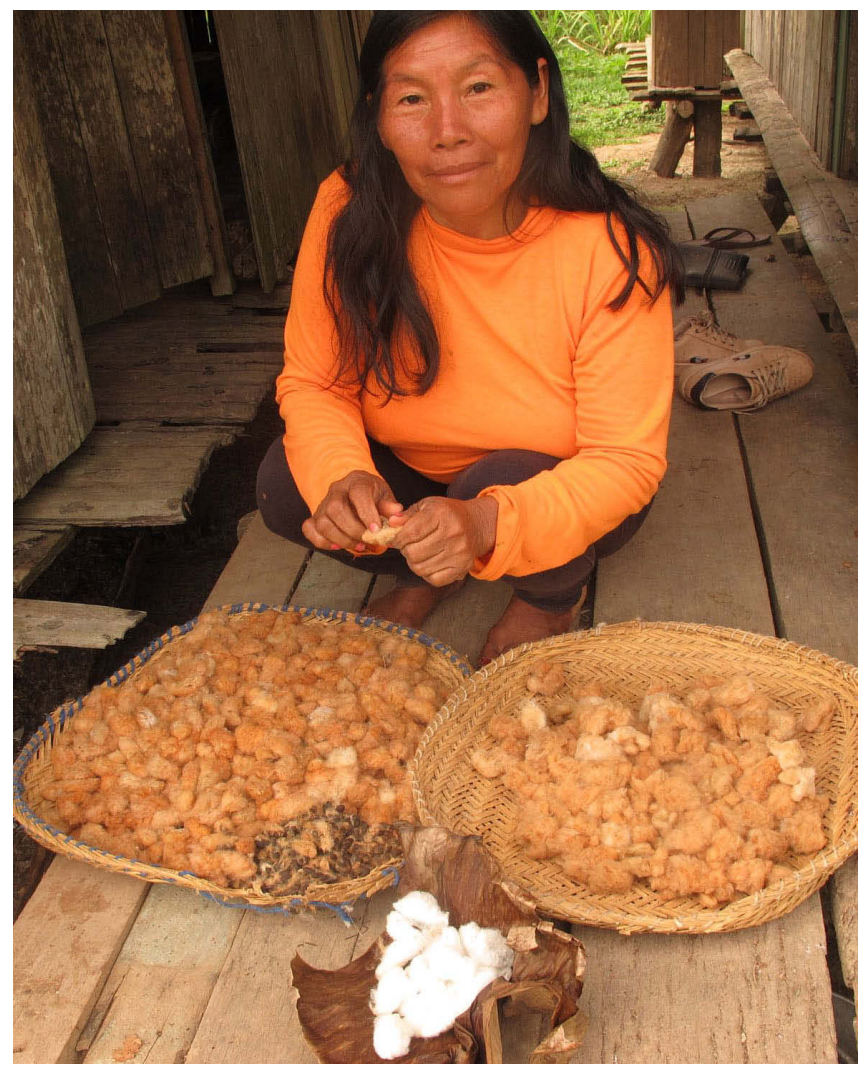

Foto 5 Experta tejedora Débora Pedro Hermes, despepitando algodón pardo. CCNN Nueva Luz 2019. Foto: M.E. del Solar

Desde las últimas décadas no es extraño observar la presencia de material sintético en el tejido, así como el empleo de anilinas para teñir el algodón, aunque resulta difícil y bastante costosa su provisión por la distancia con centros comerciales. En la pequeña colección de tejidos adquirida especialmente para el presente estudio, podemos identificar la presencia de hilo sintético de color, imitando a los tonos que tradicionalmente se emplean para la realización de los kené, especialmente el pabilo de algodón blanco industrial. Es interesante constatar con ello que existe un interés en pasar desapercibidos los nuevos materiales de origen industrial ya que la pequeña demanda existente prioriza los productos tradicionales.

\section{El hilado:}

Un buen hilado consiste en la base fundamental de una prenda de calidad. Un valor importante para calificar un buen hilado, tal como es apreciado por las mismas hilanderas, es que este sea delgado, parejo y esté bien limpio de pajillas e impurezas. La diferencia de calidad entre un tejido hecho con hilo parejo y otro con hilo desigual se observa a simple vista, mostrándose este último en una prenda de tejido flojo y rústico, con el diseño poco definido. Hemos

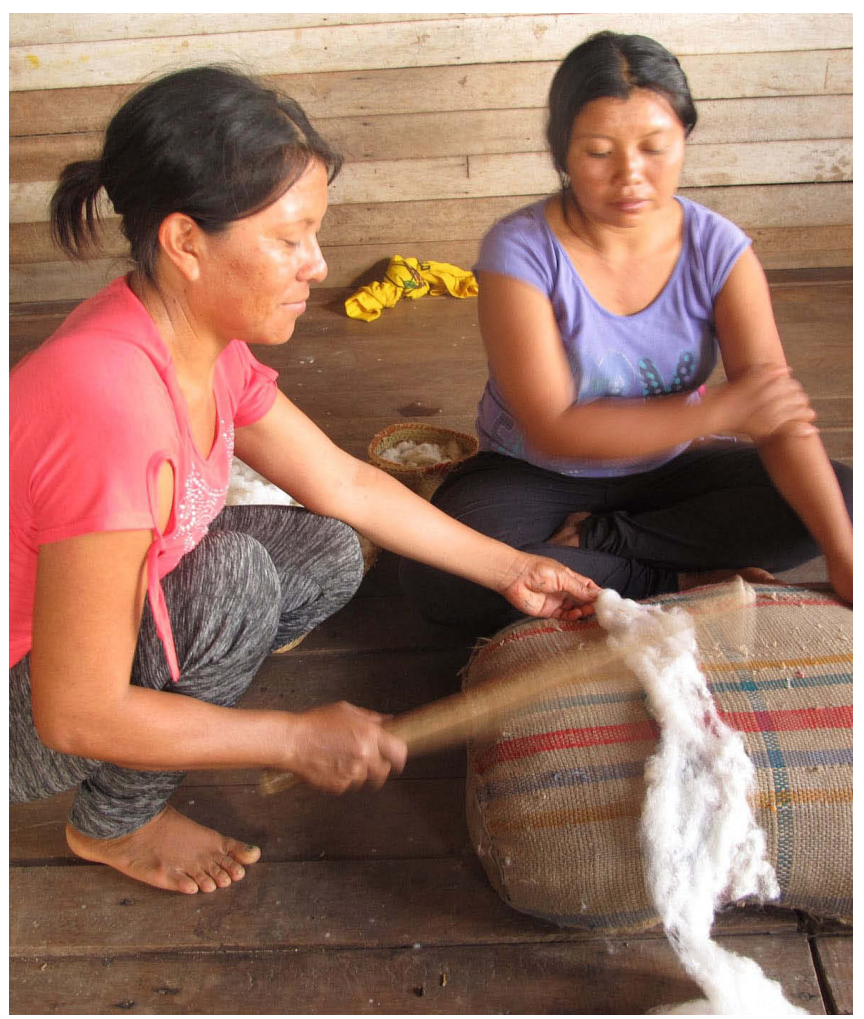

Foto 6 Batiendo la fibra para limpiar de impurezas y airear las hebras. Eleana Torres Montes, CCNN Conta 2018. Foto: M.E. del Solar

observado que la mayoría de las mujeres logran un hilado fino y parejo cuando se lo proponen ya que manejan una extraordinaria pericia para ello, producto de un aprendizaje y práctica desde muy jóvenes, aunque muchas veces no lo producen fino ni parejo ya que implica mayor inversión de tiempo.

Para producir el hilo, la primera operación es la limpieza de las semillas, agrupadas en el corazón de la cápsula (Foto 5); enseguida la fibra se extiende, se coloca sobre una almohadilla para golpearla con una varilla con la finalidad de limpiar de impurezas y separar e individualizar las hebras. (Foto 6) Se forma una mecha vaporosa y continua (Fotos 7 y 8) que se deposita amontonándola sobre una cesta de palmera -denominada localmente shapaja- asociada al depósito y procesamiento del hilo de algodón. En este punto la fibra ya está lista para iniciar el hilado propiamente, con la ayuda de un huso (varilla recta con un contrapeso de arcilla), que gira en un cuenco de cerámica decorado. (Foto 9)

El huso se sostiene siempre con la mano izquierda, no es necesario realizar una lazada hacia el extremo de la varilla, tal como se realiza en el sur andino, porque en ningún momento esta pende suelta. En primer lugar se estira la mecha, limpiando a la vez la fibra de cualquier impureza 


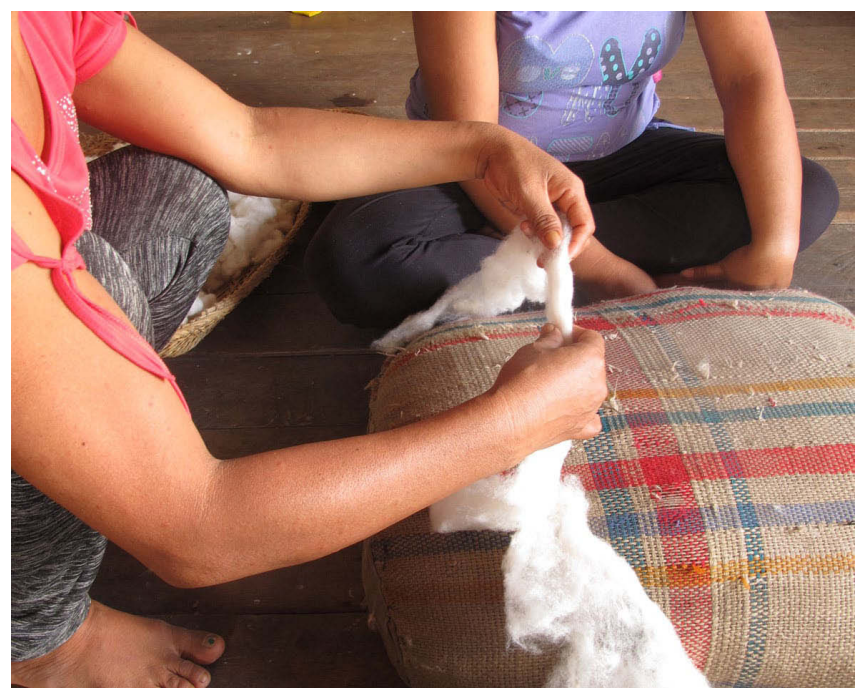

Foto 7 Se forma una mecha aireada y pareja. Eleana Torres Montes, CCNN Conta 2018. Foto: M.E. del Solar

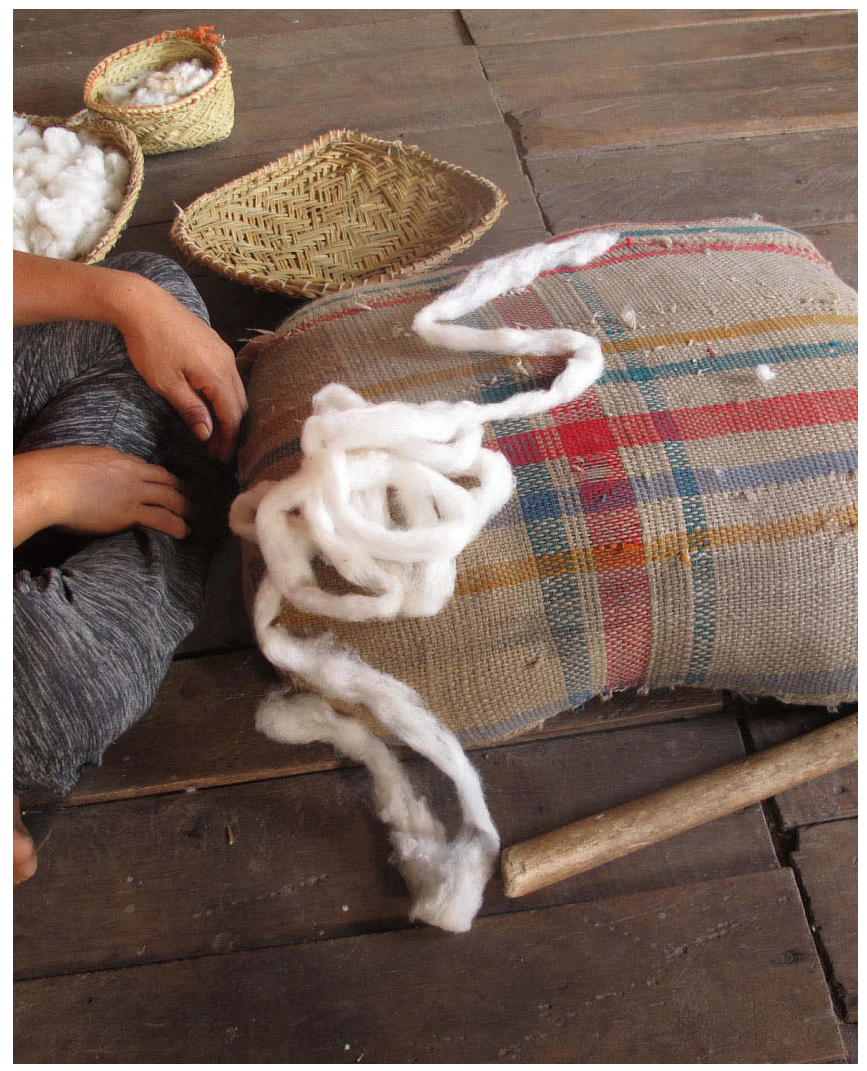

Foto 8 La mecha queda lista para el hilado. Eleana Torres Montes, CCNN Conta 2018. Foto: M.E. del Solar

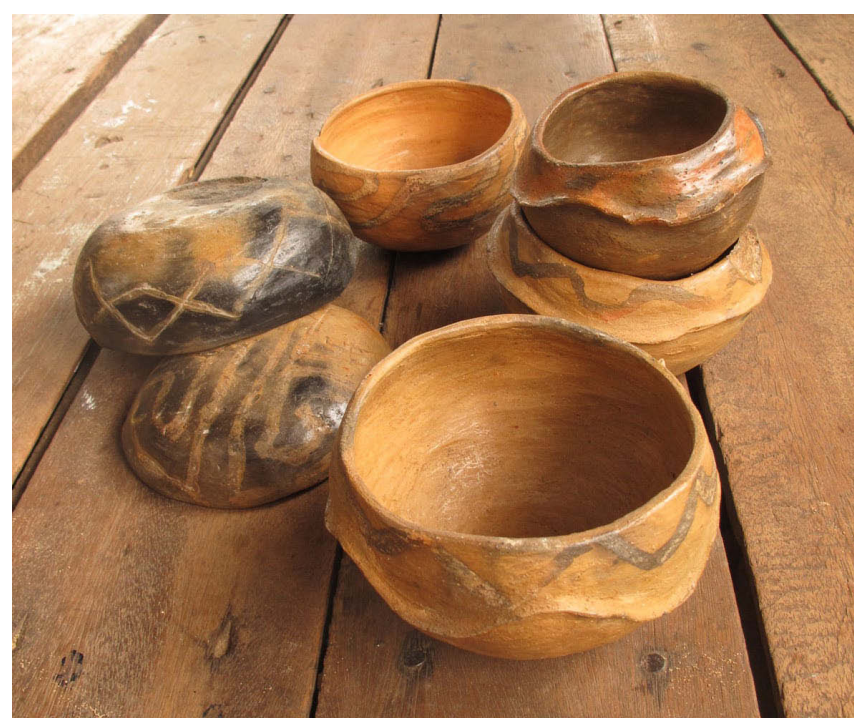

Foto 9 Cuencos de cerámica decorados, preparados por Doris Salomón, sirven para rodar el huso durante la acción del hilado. Puerto Esperanza 2018. Foto: M.E. del Solar

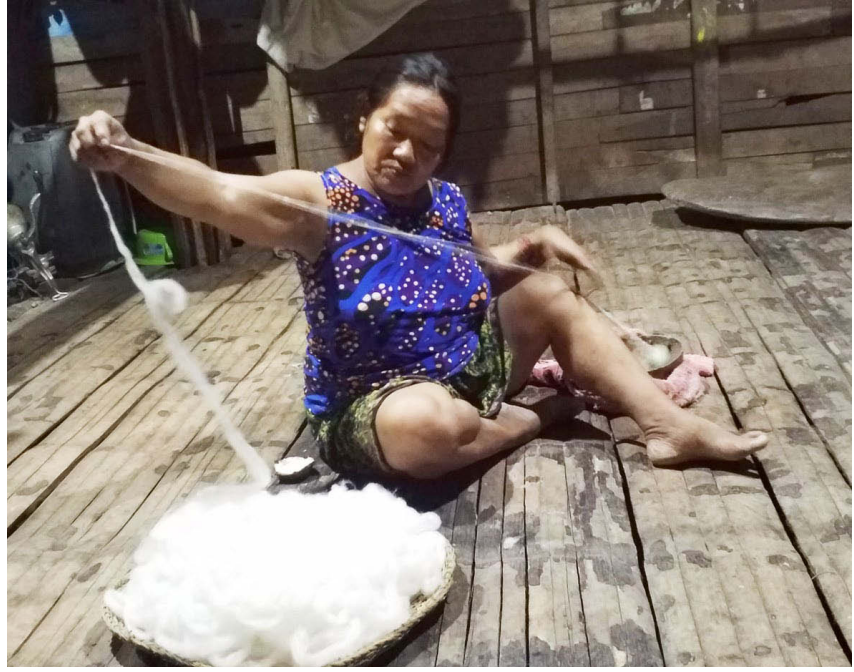

Foto 10 Proceso de adelgazamiento de la mecha para formar el hilo, obsérvese que el huso no pende durante la acción del hilado. Hilda Pinedo, CCNN Colombiana 2019. Foto: M.E. del Solar

o imperfección; acto seguido, se tuerce la fibra mediante un movimiento contra la pierna (entre el tobillo y la rodilla), haciendo girar el huso hacia la izquierda lo que produce una torsión en 'S', para finalmente enrollar el hilo obtenido sobre el huso. ${ }^{8}$ (Foto 10) Para obtener una mayor consistencia del hilo, se pliegan dos cabos y se retuercen en el sentido opuesto, llegando así a una torsión final en 'Z' para un hilo descrito 'Z2s. ${ }^{9}$

8. Las hilanderas de algodón de la costa norte del país producen igualmente un torcido en dirección 'S' mediante una manipulación horizontal del huso con la mano derecha, el hilo torciéndose en la parte inferior del huso.

9. Donde el sentido de la torsión inicial es en minúscula y el sentido del retorcido en mayúscula, para evitar toda malinterpretación. 
Las técnicas:

Todas las técnicas registradas para los tejidos cashinahuá analizados son constructivas, no se ha encontrado evidencia de técnicas supra estructurales. La técnica de construcción de la tela va a determinar su decoración, enfatizada en la alternancia de colores contrastantes para la urdimbre y la trama. Se ha constatado que por lo general en los morrales llegan a combinar entre dos y tres técnicas en la misma prenda. ${ }^{10}$

Un componente adicional está constituido por las características de los hilos, en términos de combinación de grosores, grado de torsión y cantidad de cabos (pareados o torcidos), que otorgan un relieve particular a la prenda, distinción que también será plenamente visible inclusive en tejidos con hilos de una sola tonalidad, como es la tonalidad cremosa del algodón natural.

La construcción del diseño se realiza mediante el escogido manual de los hilos de urdimbre durante todo el desarrollo del tejido. Se ha observado el empleo de lizos especialmente para el tejido de hamacas, es decir en superficies de mayor ancho y específicamente para las secciones de tela llana.

Técnica y diseño se encuentran perfectamente integrados en la noción de estilo ya que el diseño está involucrado en la misma construcción de la estructura, mediante la elección de una manera de cruzamiento de los ligamentos, que responde a un conjunto de normas culturales que rigen al grupo. Al respecto, la arqueóloga Carolina Agüero (2015:58), argumenta algunos interesantes conceptos aplicables igualmente al dato etnográfico:
Cabe señalar que muchas tipologías privilegian la decoración, pero en varios contextos el estilo decorativo es mucho menos diagnóstico de identidades sociales que las tradiciones tecnológicas. En este sentido, no es deseable separar "estilo" de "función" o decoración de tecnología. La decoración es simplemente un atributo más de la elección técnica. Entonces, estilo no es algo agregado a los objetos, sino el resultado de elecciones técnicas y decorativas, lo que en términos metodológicos entenderé como una manera característica de ejecutar, construir y diseñar...

El cruce de las tramas y urdimbres forma un ángulo recto, $90^{\circ}$, desarrollado en dos dimensiones del plano, y al tener mayormente una densidad similar en la urdimbre y en la trama el empleo de la técnica sarga genera diagonales en un ángulo de $45^{\circ}$. Esta técnica consiste en la organización de tramas y de urdimbres flotantes en tramos y dirección regulares -saltas sobre tres o cuatro urdimbres- que pueden ser hacia la derecha o izquierda, que determinan el ángulo de las líneas diagonales y, a la vez, limitan las posibilidades del diseño y van a dar lugar a una marcada tradición tecnológica regional. Por tanto, se trata de dos lecturas de una misma acción pero que separamos en dos temas, o secciones, para efectos del presente estudio: de un lado las técnicas y de otro los diseños o motivos.

Las técnicas analizadas son descritas y graficadas a continuación a partir de una muestra de 27 piezas:

\begin{tabular}{|c|c|}
\hline Técnicas decorativas & Función en el tejido \\
\hline \multicolumn{2}{|r|}{ Estructuras en los tejidos } \\
\hline Tela llana, con hilos $1 \times 1$ & Cuerpo de morrales en combinación con otras técnicas. \\
\hline Variante: con hilos $1 \mathrm{x} 4$ & Inicio y final de tejido de bolsas. \\
\hline Variante: con hilos $2 \times 2$ & $\begin{array}{l}\text { Cuerpo de morrales en combinación con otras técnicas. } \\
\text { Una hamaca con diseño de cuadros producidos por franjas } \\
\text { de urdimbres de colores diferentes y franjas de trama de } \\
\text { colores diferentes. }\end{array}$ \\
\hline $\begin{array}{l}\text { Tela llana combinada con } \\
\text { urdimbres entrelazadas }\end{array}$ & $\begin{array}{l}\text { En cuerpo de morrales (único espécimen identificado con } \\
\text { esta técnica). }\end{array}$ \\
\hline $\begin{array}{l}\text { Tela llana combinada con sarga } 3 \cdot 3 \\
\text { y } 3.1\end{array}$ & En cuerpo de morrales \\
\hline $\begin{array}{l}\text { Sarga } 3.3 \text { y derivados en chevrones, } \\
\text { rombos o ganchos }\end{array}$ & Motivos geométricos en cuerpo de bolsas y hamacas. \\
\hline \multicolumn{2}{|c|}{ Estructuras en las asas } \\
\hline Tela llana, con hilos $1 \times 1$ & En combinación con otras técnicas. \\
\hline Variante: con hilos $2 \times 1$ & Asas. \\
\hline Tela llana, cara de urdimbre & Más compacto para tejido de asas. \\
\hline $\begin{array}{l}\text { Tela llana, cara de urdimbre, con } \\
\text { hilos flotantes alternados sobre } 3 \\
\text { hilos de trama }\end{array}$ & Más compacto para tejido de asas. \\
\hline
\end{tabular}

10. No fue posible documentar en detalle el proceso del armado de urdimbres por falta de coincidencia y oportunidad. Es un pendiente importante para nuestra próxima visita a la zona. 


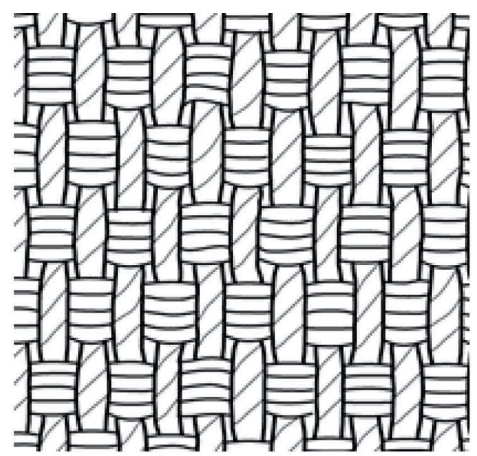

Cuerpo de morral

Tela llana. Z2s/4s

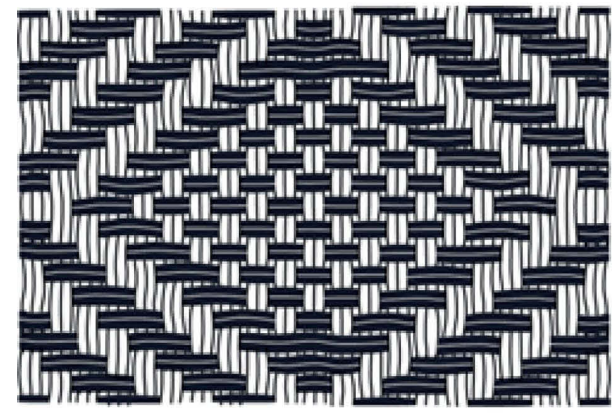

Cuerpo de morral

Combinación de tela llana y de sarga 3.3. Hilos dobles en la urdimbre y en la trama

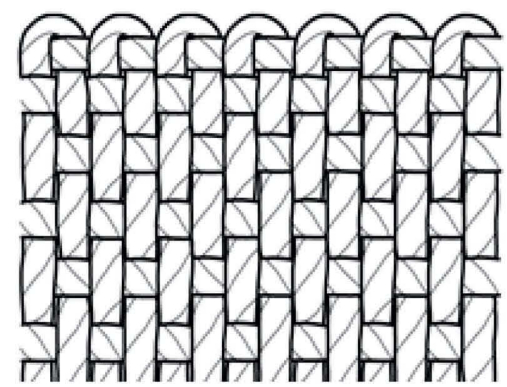

Asa de morral

Tela llana. Z2s/Z2s

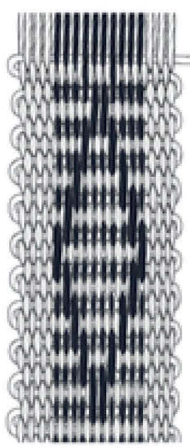

Asa de morral

Tela llana cara de urdimbre con hilos flotantes alternados sobre 3 hilos de trama

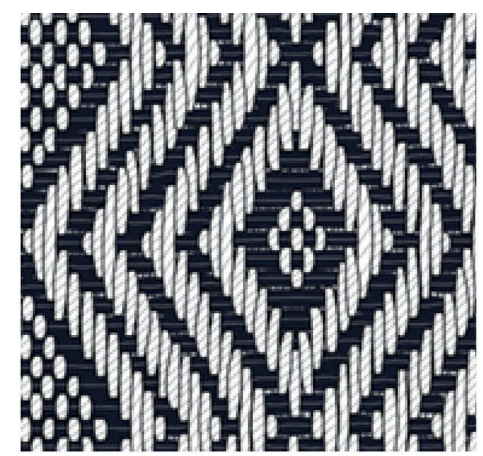

Cuerpo de morral

Combinación de tela llana y de sarga 3.3 y 3.1

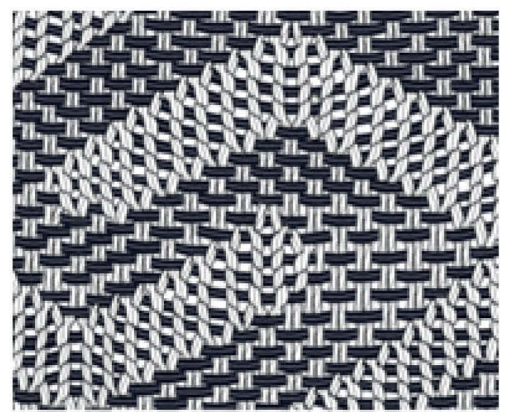

Cuerpo de morral

Tela Ilana y urdimbres entrelazadas

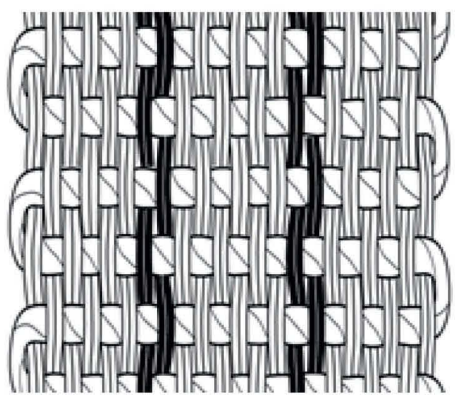

Asa de morral

Tela llana con listas de dos hilos en la urdimbre

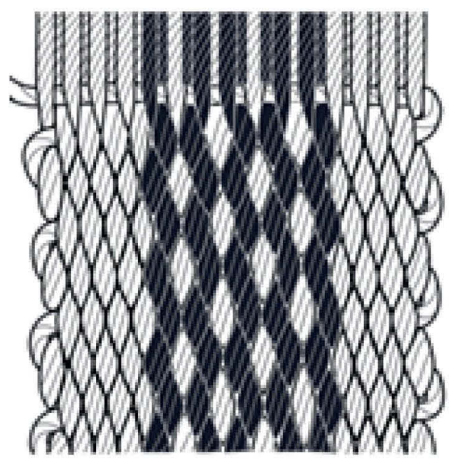

Asa de morral

Tela llana cara de urdimbre con finas listas de dos hilos separados por un hilo del color principal 


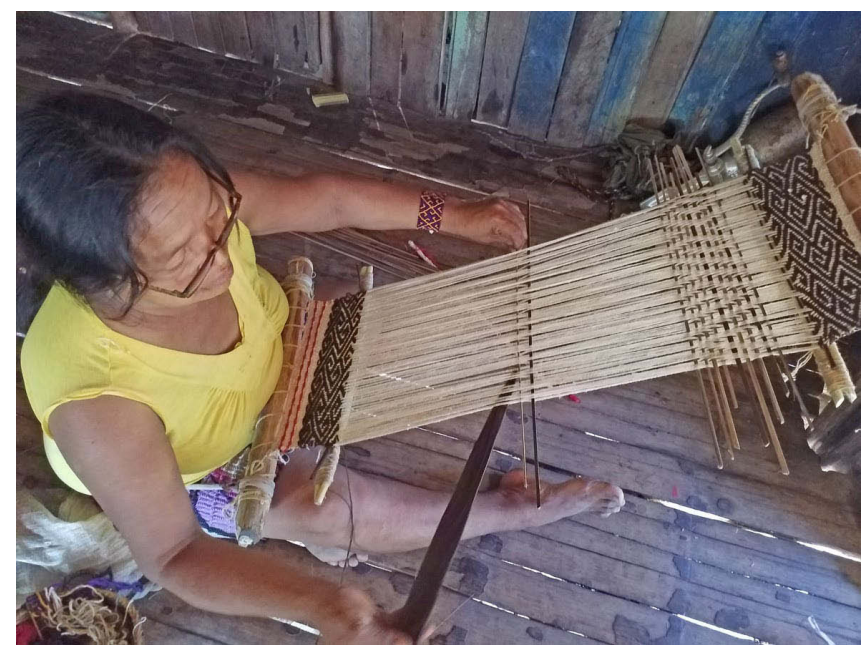

Foto 11 Aplicación del método de tejido de 'varillas de memoria' para la confección de un morral. Hilda Pinedo, CCNN Colombiana 2019. Foto: M.E. del Solar

Los hilos de urdimbre de los productos analizados están constituidos en su mayoría por dos hilos pareados; la cantidad de hilos de trama es variable pudiendo llegar hasta una cantidad de cuatro, otorgando así una mayor fortaleza a la estructura de la tela. En las asas aparecen en mayor cantidad los hilos torcidos, Z2s.

En la ejecución de la técnica sarga, recurrente en las secciones con decoración de los tejidos, se emplean dos colores contrastantes, como ha sido señalado, por lo general blanco/ negro-gris azulado. Para las tejedoras, la trama resulta más importante que el urdido (por lo general de color blanco), en la medida de que el hilo de color, es decir la trama, define el diseño por contraste.

El patrón de urdimbres flotantes alternadas sobre tres hilos de trama está directamente asociado a la estructura del cuerpo del tejido y, en algunos casos, a la generación de diseño en las asas. Esta técnica produce en las asas de los morrales un tejido más compacto, adecuado a su función de carga.

En general, la combinación de tela llana con sarga constituye la técnica decorativa más difundida. Aparece siempre cubriendo todo el cuerpo del morral, también cubriendo toda la superficie de camisas y de faldas, o en las bandas que se alternan con secciones de tela llana, en las hamacas. ${ }^{11}$

La aplicación de la técnica del entrelazado de urdimbres (warp twining), con un ritmo de cuatro torsiones hacia cada lado, combinado con tela llana, ha sido particularmente interesante.

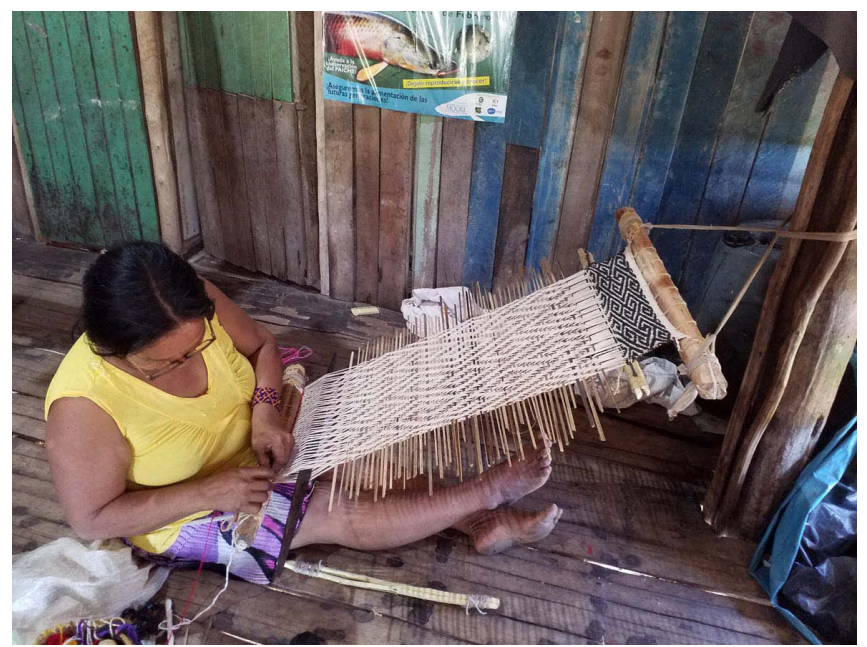

Foto 12 Una vez escogidas las urdimbres se inserta la trama y una delgada varilla en la misma calada. Esta lleva la memoria del diseño hacia la parte superior y será tejida una vez que se da vuelta el telar. Hilda Pinedo, CCNN Colombiana 2019. Foto: M.E. del Solar

\section{Técnica especial: 'Varillas de memoria'}

Se ha identificado un método de tejido entre las tejedoras cashinahuá que implica una racionalización del tiempo invertido y se aplica tanto a tejidos grandes (hamacas) como a prendas de menor tamaño. Conocemos de la existencia de este método en otros grupos de la Amazonía pero no lo hemos documentado personalmente. Sería importante constatar si aparece exclusivamente entre los grupos de la familia pano o se encuentra difundido a un nivel más amplio de la Amazonía. (Foto 11)

Durante el proceso del tejido, las urdimbres se escogen manualmente con la espada para construir el diseño por cada inserción de la trama. Una vez ajustada esta con la espada, se inserta una varilla de hoja de palma en la calada para controlar y subir el diseño a la parte superior del telar -si se teje con lizos, la varilla se insertará inmediatamente después de estos- donde se van acumulando las varillas que van guardando la memoria del diseño. En este punto, el telar se da vuelta y se teje la sección con varillas, donde el diseño ya se encuentra escogido, simplemente introduciendo la espada para retirar una a una las varillas e insertar la trama sin tener la necesidad de escoger los hilos de urdido nuevamente. (Foto 12) Este proceso permite acelerar el tejido, ahorrando tiempo y esfuerzo, ya que el diseño se encuentra planteado en las varillas, a modo de espejo. (Foto 13)

A continuación, se procede a la misma operación, subiendo las varillas con la información del diseño que ha sido

11. En el artículo de Helen Tanner (1975:119 y 121), aparece también una manta totalmente decorada, así como otra con decoración de franjas con plumas y conchas superpuestas, supuestamente parte del ajuar empleado por el maestro en ceremonias de iniciación. 


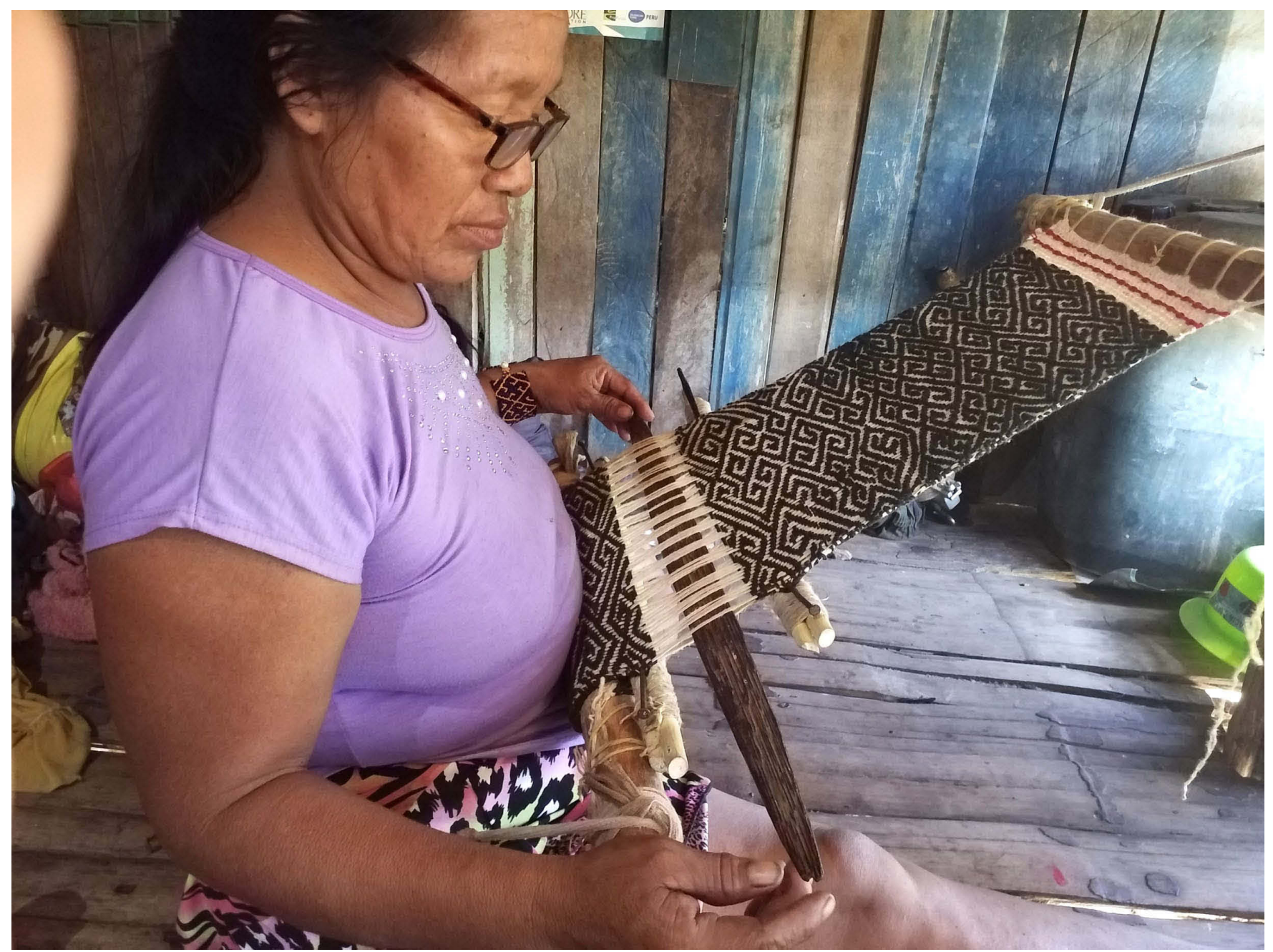

Foto 13 La información del diseño queda planteada a modo de espejo. Hilda Pinedo, CCNN Colombiana 2019. Foto: M.E. del Solar

tejido en la parte inferior, tantas veces como se considere conveniente y que el espacio libre lo permita.

Cuando se alcanza el eje de simetría, ya sin mayor espacio para introducir la espada, se continúa con el desarrollo del tejido mediante el empleo de una aguja, replicando el diseño hasta alcanzar la coincidencia adecuada.

La cantidad de varillas empleadas varía en función al diseño que se aplique, aunque en tejidos de mayor dimensión, particularmente en las hamacas, con diseños de mayor envergadura, se puede llegar hasta 100 varillas, señala la Sra. Hilda Pinedo de la CCNN Colombiana.

Se ha documentado la técnica de telar de 'varillas de memoria' con todas las tejedoras cashinahuá entrevistadas en el alto Purús y en el Curanja, así como en las poblaciones migrantes de los poblados de Puerto Esperanza y Pucallpa, por lo que consideramos el empleo de las varillas que retienen el diseño como un patrón común a esta cultura textil. Hay una racionalidad creativa en esta manera de tejer que representa una reducción importante del esfuerzo invertido con relación al tiempo de trabajo.

Encontramos este mismo sistema de trabajo pero con diferente propósito en otras zonas de Perú y América. Es similar entre las tejedoras yaminahua, ubicadas en la misma región, para la elaboración de hermosos brazaletes en fibra de chambira, en rústicos telares armados sobre ramas torcidas, conocidos como 'telares de arco'.12 (Foto 14) Es probable que toda la región de los ríos Curanja y Alto Purús presente similar procedimiento. ${ }^{13}$

\section{Agradezco la observación a Ann P. Rowe.}

13. Inclusive hacia el norte de la Amazonía peruana se tiene referencia de los tejidos matsés elaborados con la misma técnica, lo que permite plantear una distribución bastante más amplia, es probable que a nivel de tradición Amazónica, aún pendiente de documentar para enriquecer los estudios en la línea de trabajo iniciada. 


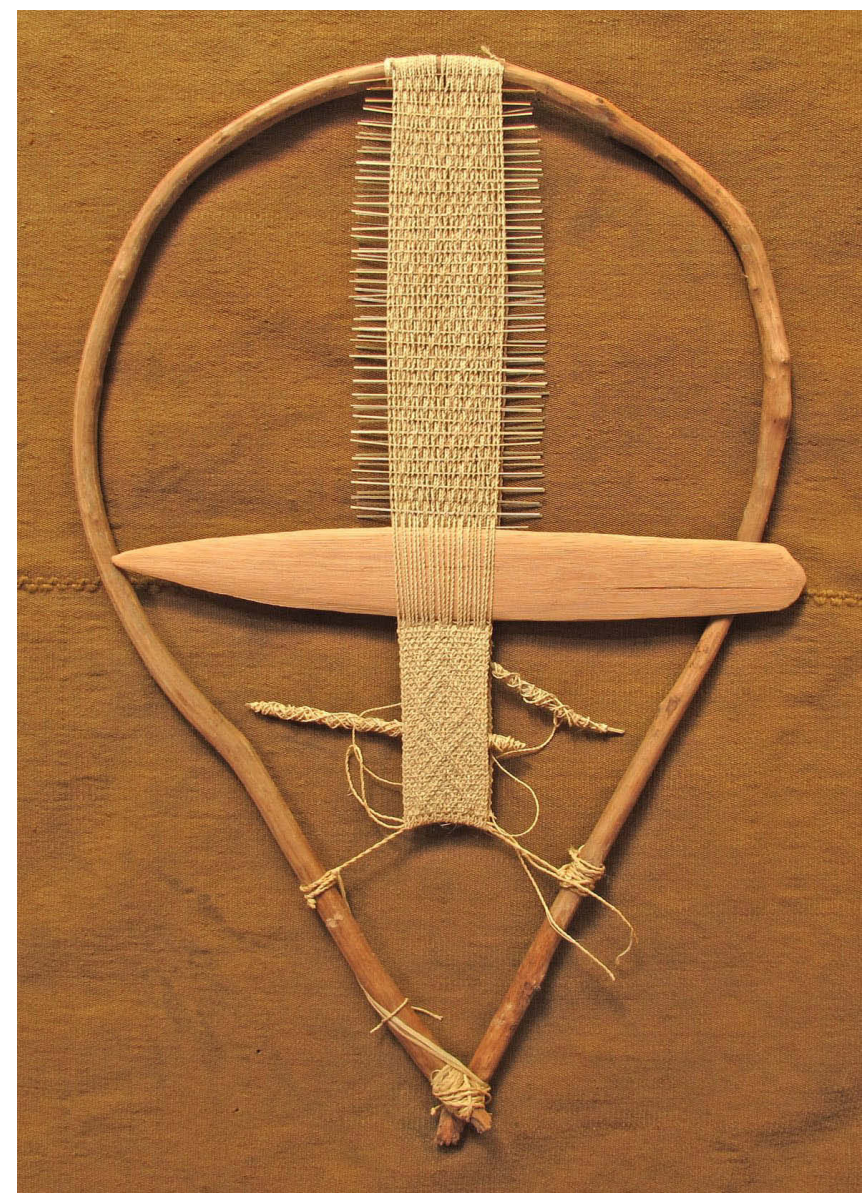

Foto 14 Pulsera de chambira en 'telar de arco'. Pueblo yaminahua, río Purús. Foto: M.E. del Solar

En el tejido de la bolsa en técnica sprang de las tejedoras Mosetene de Bolivia, los palillos memorizan el diseño temporalmente hasta la finalización de la obra en que las urdimbres quedan fijas por lo cerrado del tejido. (Foto 15)

Un sistema diferente se observa en el tejido de las fajas 'sara' en San Ignacio de Loyola, en la sierra norteña peruana. (Foto 16) Allá, las urdimbres se escogen y disponen sobre varillas destinadas a plantear el diseño, previo a la elaboración de los lizos o chuguays, que permiten repetir el diseño memorizando el número de veces que se quiera sin la necesidad de invertir más tiempo en el escogido. ${ }^{14}$ Por ejemplo, una faja de $395 \mathrm{~cm}$ de largo (área tejida), puede tener el mismo diseño repetido 61 veces. ${ }^{15}$

Los cashinahuá emplean estas varillas solamente para el tejido del cuerpo de las bolsas o de las bandas con diseño de las hamacas. En este último caso, el telar puede llevar

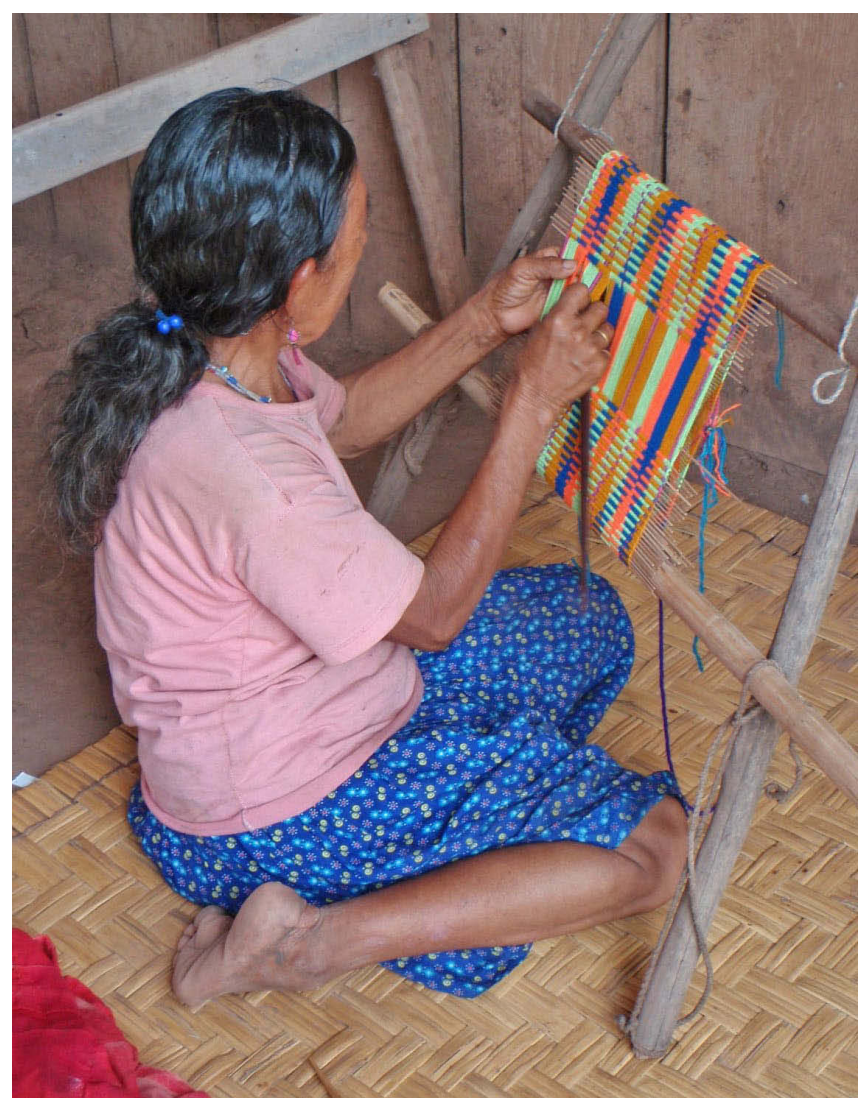

Foto 15 Bolsa, técnica sprang. Tejedora Mosetene. Tierras bajas. Bolivia. 2009. Foto: I. Daillant

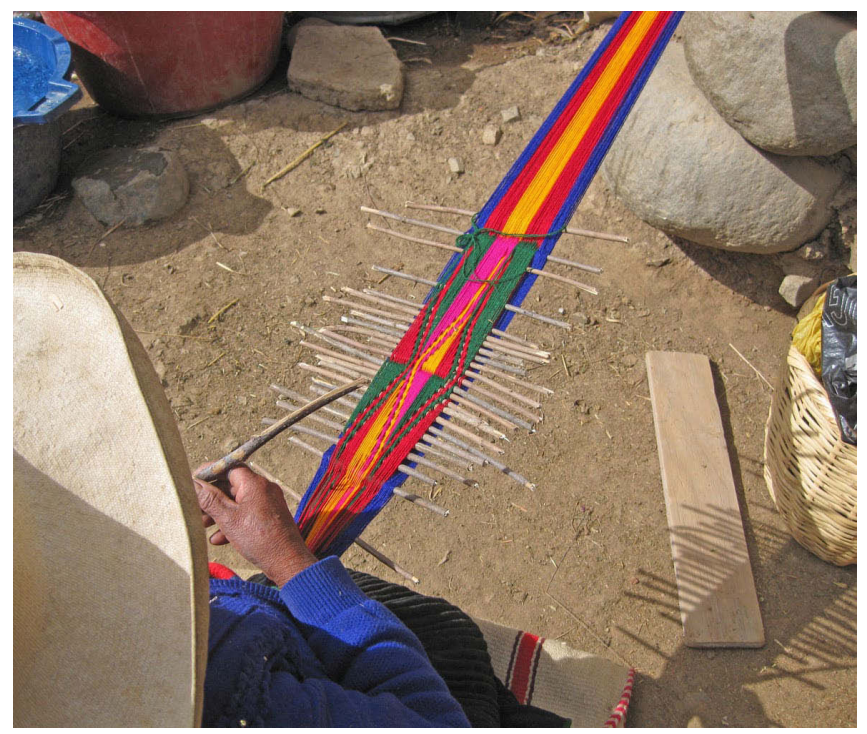

Foto 16 Faja sara. Proceso de montado de los lizos a partir del diseño levantado en las varillas. Sierra norte. La Libertad, 2012. Foto: S. Desrosiers

14. El tema ha concitado la atención de estudiosos como: Fernández 2007, 2014; Meisch 2006, 2007.

15. Se tuvo la oportunidad de apreciar en campo a la tejedora Filomena Escobal Dionicio comprobando la efectividad del sistema al realizar correcciones durante el proceso de preparación del apartado de las urdimbres, previo al tejido. 
tanto lizos como varillas, de acuerdo a su función diferenciada: ayudar en la producción de la estructura para los lizos o memorizar el diseño para las varillas.

\section{Los “tejidos verdaderos" de los cashinahua}

\section{Geometría simbólica e interpretación social:}

Uno de los mitos de origen de los cashinahuá narra que el grupo decide abandonar sus tierras en el centro del mundo en busca del metal para producir armas y herramientas necesarias para su subsistencia. Encuentran un gran río en su camino y un enorme caimán dormido, Kape, les sirve de puente para alcanzar la orilla opuesta a cambio de alimento. Todo el grupo no logra atravesar pues el caimán se enfurece al ver que han matado a su hermanito caimán, que le ofrecen como alimento. Los que logran atravesar el río van a una tierra buena y tendrán acceso al metal para adornos y herramientas; son los antepasados de los Incas y de los blancos, por lo tanto nawan, no indios, foráneos, mestizos. Aquellos que no lograron pasar regresan al centro del mundo, sin metal; son los antepasados de los indígenas, huni kuin, es decir personas verdaderas.

(Fuente: Deshayes y Keifenheim 2015)

Entonces, de esta manera, el kuin representa el punto de vista de los huni kuin, o del hombre verdadero, que es así como se llaman a sí mismos en la actualidad. De otro lado, kené significa diseño, escritura, gráfica, por tanto kené kuin va a representar entonces al diseño auténtico, propio. Así, el apelativo de 'tejidos verdaderos' se entiende asociado al diseño, kené, en contraposición al nawan kene, siendo nawan principalmente, un gentilicio empleado para denominar al 'otro', al 'foráneo', al mestizo, al 'no-pariente'. Por tanto es una voz empleada para señalar los tejidos ajenos, los tejidos no reconocidos como propios. (Foto 17)

El tejido cashinahuá se diferencia notablemente de otras expresiones textiles contemporáneas de la Amazonía peruana por la complejidad de sus técnicas y el carácter de sus diseños. El kené es un patrón decorativo esencialmente gráfico que se aplica a la cerámica, la cestería, la pintura corporal y los tejidos, común a los grupos pertenecientes a la familia pano, nos referimos especialmente a los diseños que distinguen a los shipibo-conibo del Ucayali y a los cashinahuá de las cabeceras de los ríos Purús y Curanja. Aunque, se observa una marcada diferencia en el tratamiento técnico contemporáneo de ambas interpretaciones del kené

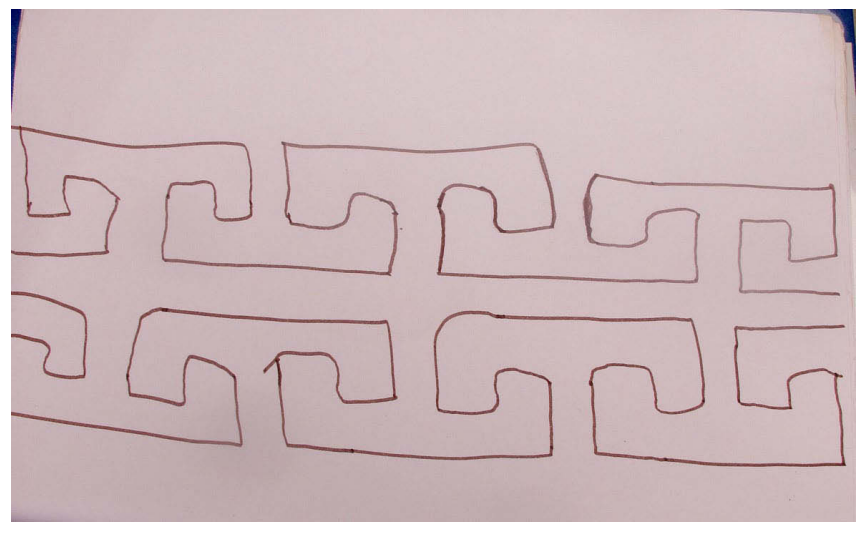

Foto 17 Dibujo de nawan kene. Eliana Torres Montes, CCNN Conta 2018. Foto: M.E. del Solar

en los tejidos de ambos grupos. En el primer caso, se destaca la complejidad del kené shipibo-conibo, pintado o bordado sobre la superficie de la tela - tela industrial de tocuyo o cañamazo, o, con una presencia cada vez más reducida, confeccionada en telar de cintura - , con respecto del segundo caso, la modalidad cashinahuá, que consiste en la ejecución del kené mientras se construye la tela, como parte de su estructura, es decir se diseña al mismo tiempo que se teje.

Sea cual fuere el soporte material, cerámica, cestería, tejidos de algodón o el cuerpo humano, el kené cashinahuá es un arte practicado exclusivamente por mujeres, aunque los objetos puedan ser empleados por toda la comunidad. La estudiosa Luisa Elvira Belaunde (2009:18) observa que en las dos últimas décadas algunos hombres shipibo-conibo han aprendido a pintar y bordar diseños kené debido a la demanda de un mercado creciente.

En la misma fuente, Belaunde (2009:22), explica que la finalidad del kené shipibo-conibo es estética y terapéutica, embellece a las personas y las cosas con los grafismos de la energía de las plantas. También las cura de males de origen físico, psicológico, social y espiritual, tanto en cuanto a la materialidad de los diseños sobre los cuerpos como en la visión inmaterial de los diseños durante las sesiones chamánicas con ayahuasca. Al respecto señala Els Lagrou (2009:90), la función del diseño cashinahuá sería la de distinguirlos de sus vecinos marcando su especificidad estética.

El diseño funciona como una metáfora, señala Lagrou (2009) para los cashinahuá de Brasil; es decir, traza caminos entre mundos separados o entre lados complementarios del mismo mundo, así como entre los estados complementarios del ser o de la conciencia humana. Los diseños son vistos en estado de vigilia y en los sueños. Concordamos con lo que subraya Lagrou (2009:87), en donde el arte gráfico aplicado en la decoración corporal sirve para señalar una relación entre el mundo de los humanos y el mundo de 
los espíritus. Podemos aplicar la misma noción, destacada por las tejedoras de la zona de estudio cuando explican los diseños textiles en relación a la importancia del conjuro, es decir, a la necesidad de recordar a los espíritus fuertes del bosque invocando su protección.

La iconografía de los grupos que habitaron en la región del alto Purús y alto Curanja debió nutrirse sin duda de fuentes muy diversas, como diverso es su territorio, en amplitud y en recursos de flora y fauna, así como variadas fueron las actividades desarrolladas por el hombre para resolver su subsistencia hasta el día de hoy. Todo ello deja una impronta en el modo de vida de las sociedades, que va a plasmarse a nivel simbólico en su cultura material, expresando al mundo que los rodea. Figuras y diseños similares se repiten en los textiles kené, en la decoración de la cerámica y en la pintura corporal, con ligeras variaciones estilísticas o debidas al grado de habilidad de las tejedoras. Su interpretación sufre modificaciones o las nomenclaturas se han perdido en el tiempo. En otros casos, la tejedora describe puntualmente la imagen sugerida por el grafismo textil pero no la reconoce por un nombre dado.

La representación de ideas propias de la sociedad que las origina se puede asociar igualmente a mitos de origen, tal es el caso de la presencia de caminos (sepi) en el mito mencionado anteriormente, tanto en la imagen textil como en el apelativo y sus variantes, especialmente en el caso de los morrales. Aquellos hombres y mujeres cashinahuá que consiguen atravesar el río van a conforman el conglomerado del apelativo mestizo, nawan, que incluye a los no parientes, los ajenos y hasta a los Incas. Los hombres y mujeres que no alcanzan atravesar regresan al mundo de sus antepasados, son huni kuin, es decir 'hombres verdaderos'. De allí la importancia de los caminos para la identidad huni kuin. Los caminos que conducen a través de la selva a la lupuna, dice otro mito, árbol de gran tamaño, xunu, sembrado y cuidado celosamente por el Inka, y cargado de bellas cuentas coloridas. ${ }^{16}$ (Foto 18 )

El mundo que les rodea está especialmente representado en su iconografía textil, es decir la densidad del bosque en las diversas capas y texturas del tejido, la vegetación exuberante y profusa en la representación recargada de diseños sin descanso de los morrales, a modo de 'horror al vacío'. El estilo geométrico-abstracto desarrollado en el arte textil cashinahuá guarda diseños que son explicados por las tejedoras como: cabeza o espalda de mantona, cola de lagarto, costado de boa, ramas de árbol de lupuna, semillas, hojas de palmera, escamas de pez, etc., llevados a un extraordinario nivel de estilización, que a la vez permite reconocer,

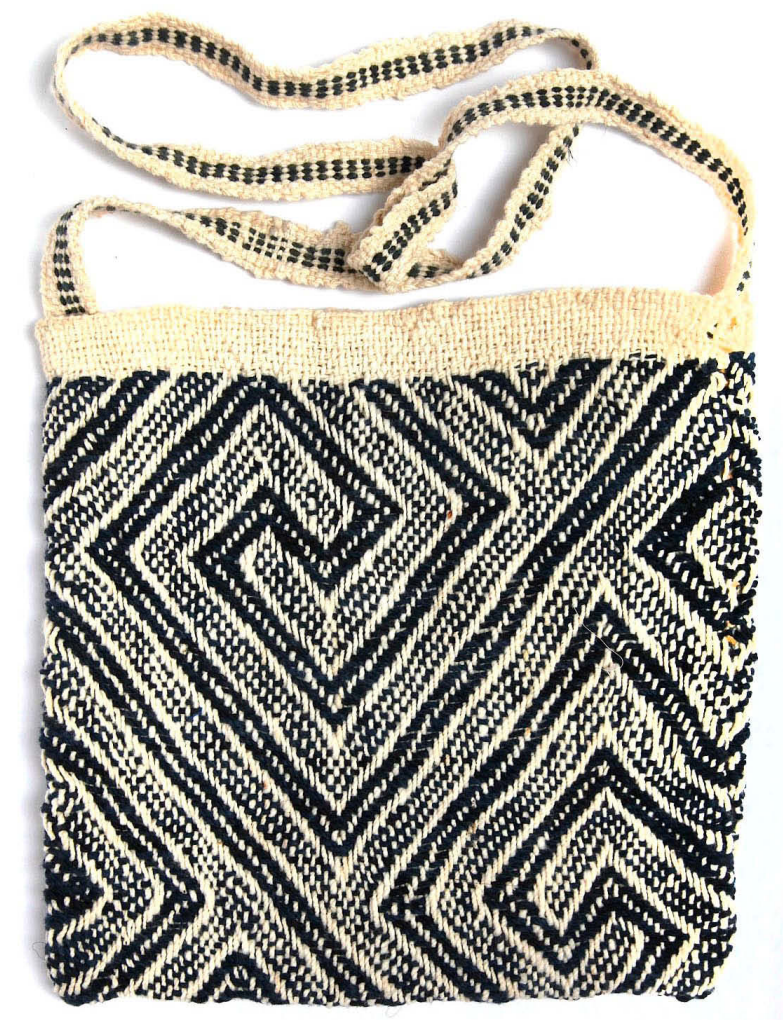

Foto 18 Morral con diseño de ramas de lupuna, xunu kené. Amerika Comapa, CCNN San Martín 2019. Foto: B. Hare

en una primera mirada, las formas aludidas y representadas, además del estilo particular de la decoración de esta cultura. Son las formas de la naturaleza, del medio que las rodea y que hacen parte fundamental de su modo de vida. (Foto 19 y 20)

No hemos encontrado indicios de renovación o de innovación de los diseños, aparentemente todo el repertorio forma parte del lenguaje textil tradicional -con algunas variantes comunes a todo el grupo cashinahuá, incluyendo a los parientes brasileros- heredado de madres y abuelas. Más adelante, se podrá observar en el registro de nombres una diversidad de apelativos diversos para el mismo diseño ${ }^{17}$, o por lo general una pequeña diferencia que poco varía el sentido de la designación. Por ejemplo, tenemos: bashu xaka, pescadito de tawampa o traducido igualmente como escama de shiruy o, para un mismo morral, dunu mapu (cabeza de culebra) y dunu kate (espalda de culebra); también, ojos de lorito u ojos de lorito 'apiñados', para designar al mismo gráfico. Otro diseño fue señalado diferenciadamente como xenpan pei (palmera shapaja) y como xena hexe (semilla de shimbillo), aunque ambos nombres hacen referencia a la flora local. 


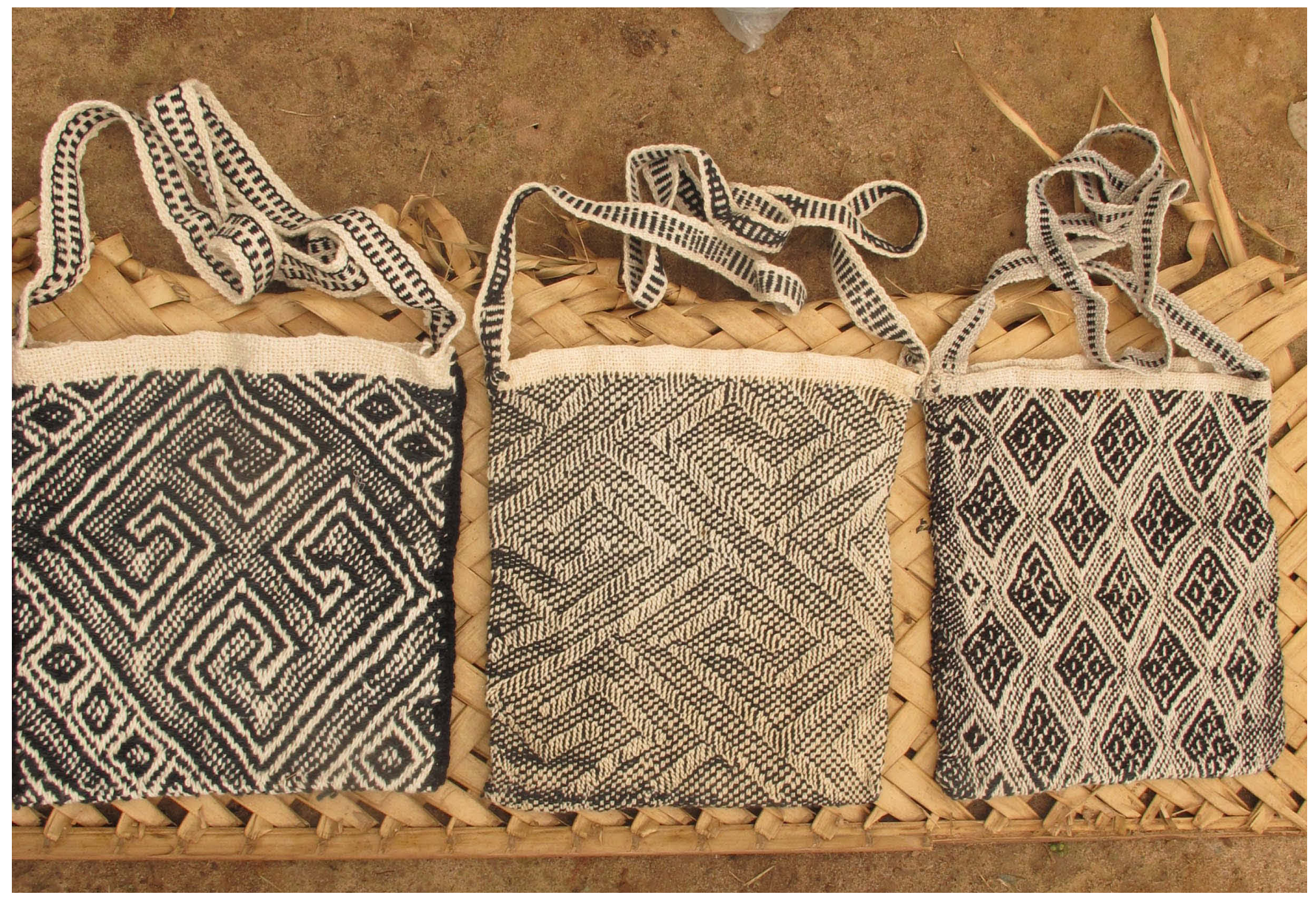

Foto 19 Diseños, de izq. a der.: a) xunu kene, rama de lupuna; b) umin kene, diseño torcido; c) inutai txede bedu, pisada de tigre en ojo de loro. Doris Salomón, Nueva Esperanza 2018. Foto: M.E. del Solar

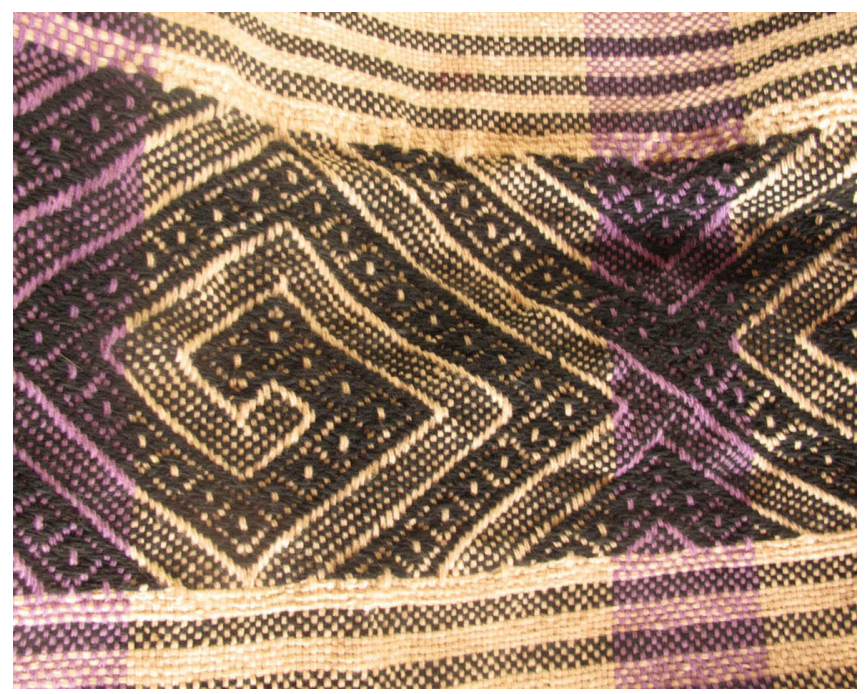

Foto 20 Detalle de hamaca con un diseño nibu hina, rabo de escorpión. María Castillo, CCNN Conta 2018. Foto: M.E. del Solar
Los diseños presentan múltiples variantes que consideran inversiones o transposiciones, redundancias o sobre repetición en las líneas dobles, triples y más, que remarcan el motivo destacado -sobre la base de los mismos diseños básicos-, una geometría en movimiento, vibrante, que, desde nuestra mirada occidental, puede confundir la comprensión del kené. Llama especialmente la atención la composición de los diseños en secciones de la prenda, en donde se muestran porciones ampliadas o parciales del mismo que producen impresiones visuales diversas (Dawson 1975:137), en una aparente asimetría enfatizada por las líneas diagonales del dibujo.

Lagrou (1990:93) observa el cambio de perspectiva entre fondo y figura de los patrones laberínticos de la cestería de otras sociedades amazónicas, que podemos extender igualmente a los tejidos cashinahuá. Al respecto señala Alice Dawson (1975:146), que el empleo de los aspectos positivo y negativo de un diseño (en la textilería) sería otra razón para sugerir que estas formas (en la cerámica) han sido por lo menos influenciadas por prácticas de tejido, si es que no han sido originadas por ellas. ${ }^{18}$ 


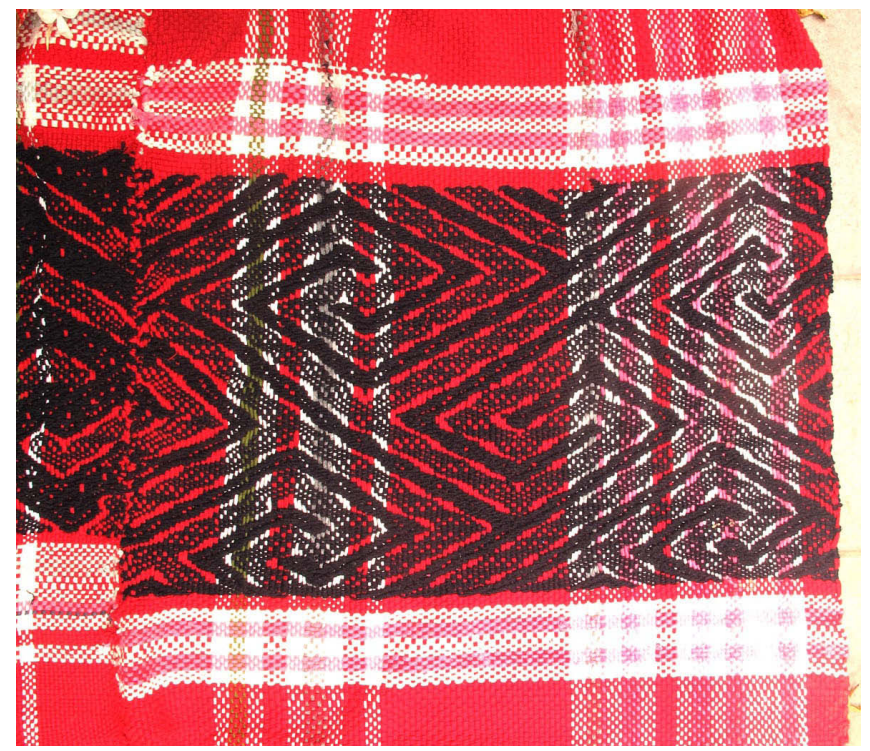

Foto 21 Detalle donde se observa el efecto de asimetría y el diseño incompleto o cortado en la sección decorada de una hamaca del Purús. Es una constante en la decoración cashinahuá. Material sintético. CCNN Conta 2018. Foto: M.E. del Solar

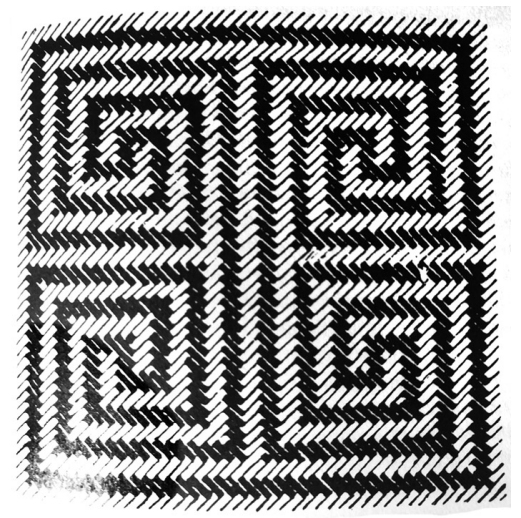

Foto 22 Detalle de diseño awidi, serpiente coralillo, en canasta asargada. Yekuana, Guyanas. En: D. Guss (1989: 107)

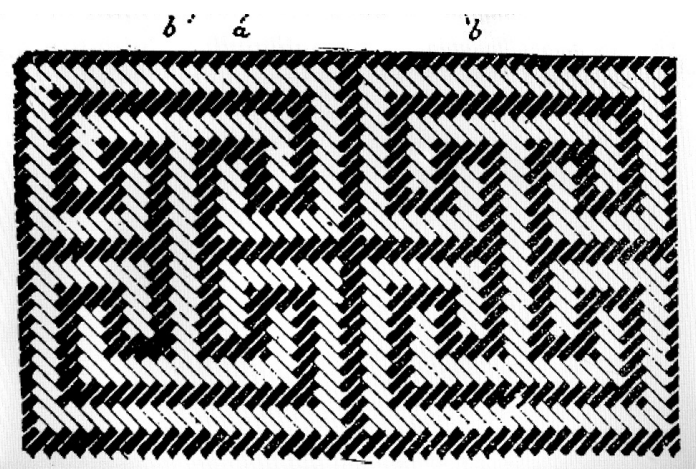

Foto 23 Diseño ‘hueso del diablo’ en canasta asargada (ver Foto17). En: D. Guss (1989:106)

18. Original en inglés, traducción propia.

19. Sophie Desrosiers, comunicación personal, setiembre 2019.
La direccionalidad de las líneas diagonales del kené está determinada por la técnica de sarga aplicada en las secciones con diseño, que limitan el grafismo a un grado de inclinación preciso, con pocas alternativas de juego. (Foto 21) Un argumento que amerita mayor profundización se refiere a la existencia de diseños muy similares provenientes de otras zonas de la Amazonía lo cual nos plantea algunas preguntas que remiten a las condiciones de movilidad de los grupos -y también de los objetos- a la circulación de bienes y de personas, inclusive pertenecientes a diversas familias étnicas.

Vemos la aplicación de la misma técnica de sarga en el tejido de canastas, tradicional a muchos grupos de tierras bajas tropicales, las mismas que presentan entonces similar contrapunto de colores y direccionalidad diagonal en los diseños, determinados por la técnica constructiva. Esta argumentación, podría apoyar el planteamiento de que la confección de tejidos habría posiblemente derivado de la práctica del manejo de fibras vegetales semiduras. ${ }^{19}$ Es muy común el empleo de la sarga en la cestería, en la cual el diseño está involucrado en la misma construcción de la estructura. (Fotos 22, 23, 24 y 25)

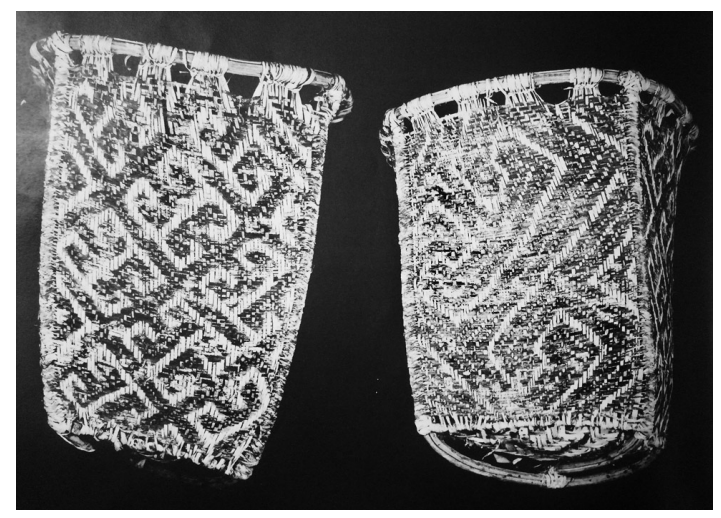

Foto 24 Canasta cashinahuá con técnica asargada en fibra teñida y natural. Izq. Diseño de ganchos en un lado de la canasta, kuki. Der. Diseño en tres lados de la misma canasta. En: Dawson (1975:136)

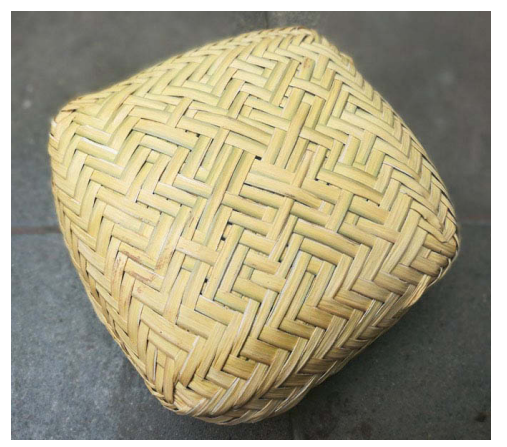

Foto 25 Base de canasta cashinahuá contemporánea tejida con técnica asargada en fibra de palma, shapaja. Doris Salomón, CCNN San Martín 2018. Foto: M.E. del Solar 
Si bien se ha identificado algunas piezas textiles con diseños que cubren toda la superficie de la prenda, como es el caso de algunas hamacas y faldas (Fotos 1 y 26), Dawson (1975:142), señala, específicamente para las hamacas, la elección de un diseño básico, que puede ser agrandado, reducido o cortado arbitrariamente en secciones que adquieren el aspecto de 'ventanas' a través de las cuales se muestra la porción de un diseño que podría ser infinito. (Foto 27) Para Lagrou (1990:59), el patrón de diseño recortado justamente en el punto cuando es posible reconocerlo, requiere de capacidad imaginativa para percibir la continuación del patrón mediante una visión mental y constituye una de las características estilísticas más saltantes del tejido cashinahuá. (Foto 28)
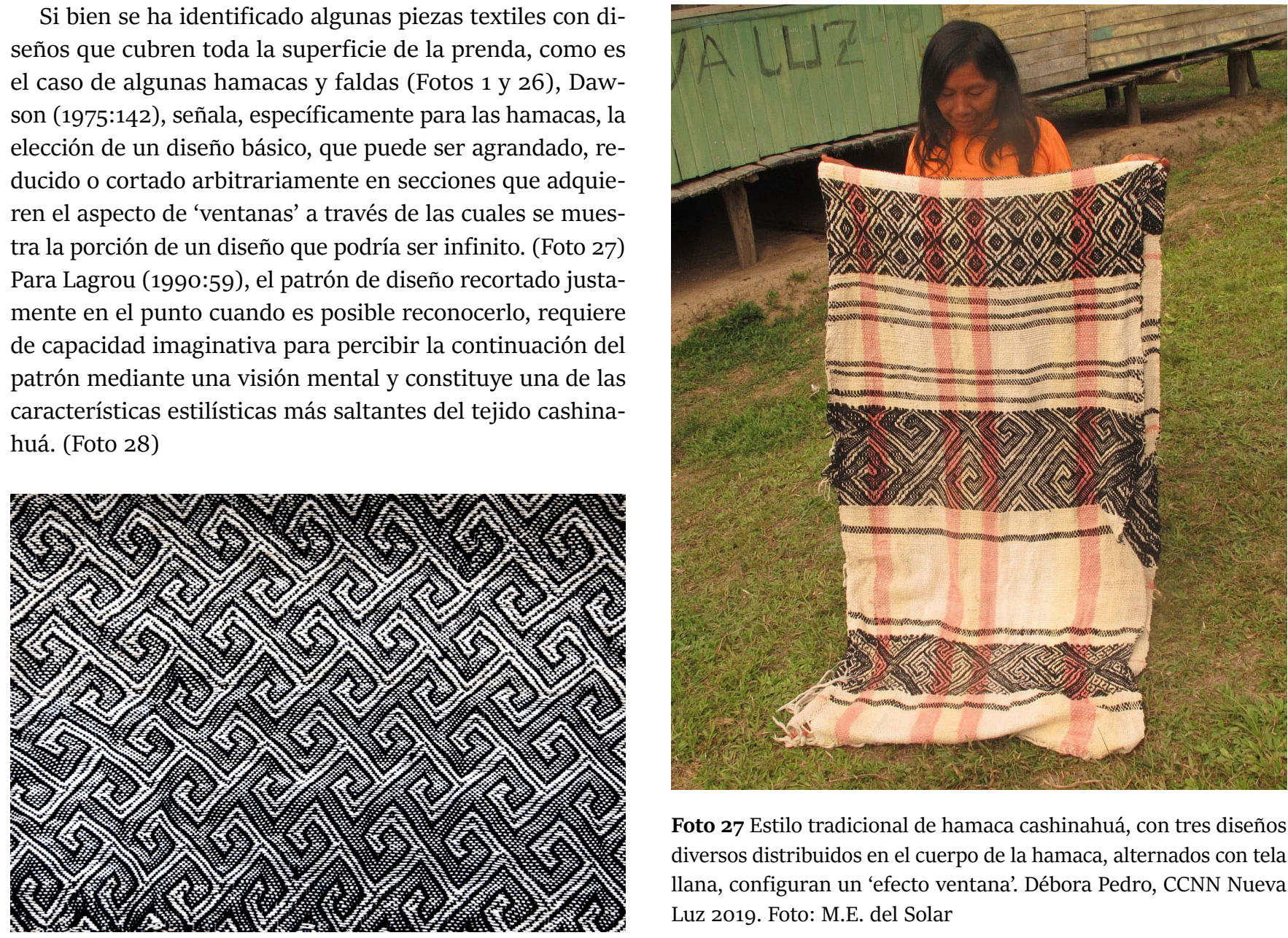

Foto 27 Estilo tradicional de hamaca cashinahuá, con tres diseños diversos distribuidos en el cuerpo de la hamaca, alternados con tela llana, configuran un 'efecto ventana'. Débora Pedro, CCNN Nueva Luz 2019. Foto: M.E. del Solar

Foto 26 Falda tejida en telar de urdimbres contínuas con diseño mae muxa, uña de gato, en toda la superficie de la prenda. Florinda Montes, CCNN Conta 2018. Foto: B. Hare

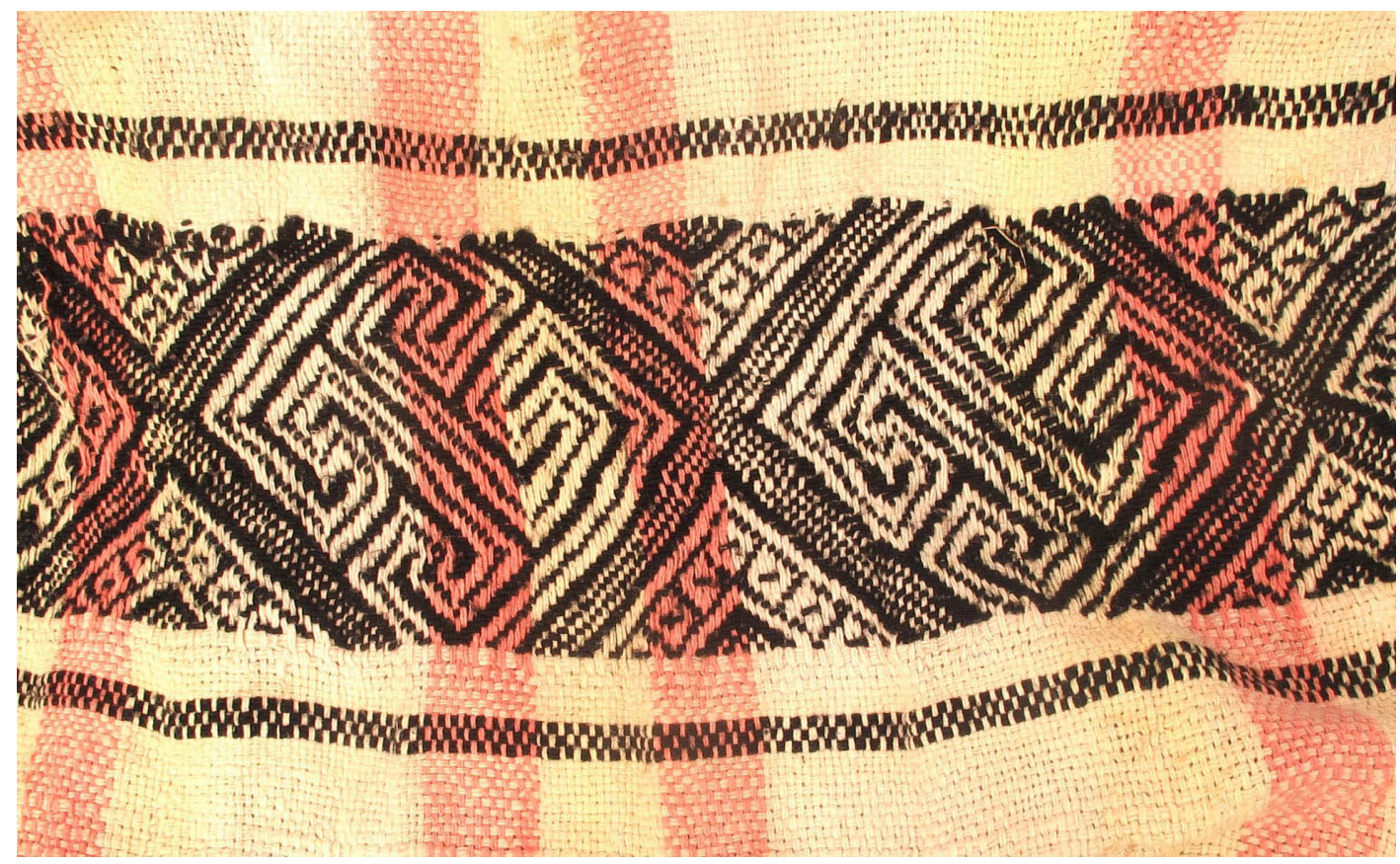

Foto 28 Detalle de anterior, diseño macaco kené. Foto: M.E. del Solar 


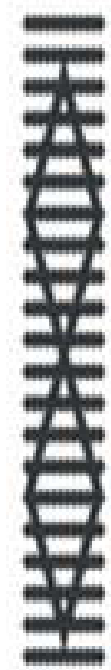

Kaxau jina, cola de guacamayo

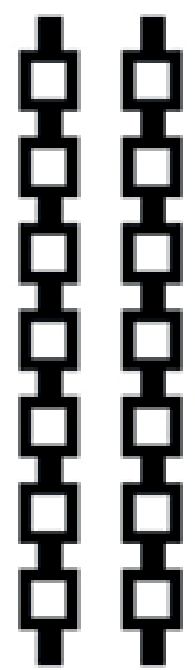

Xena dabe, dos gusanos

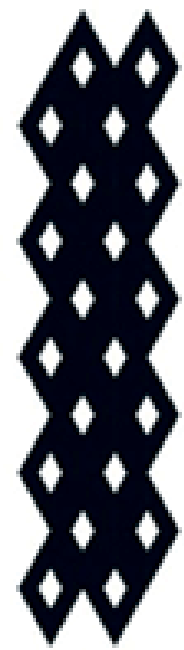

Xapu bexe, pepita de algodón

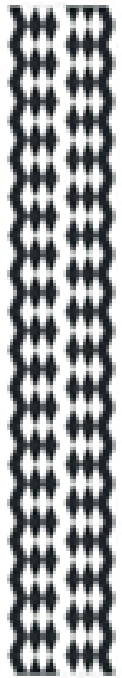

Kaman betu, frente de perro

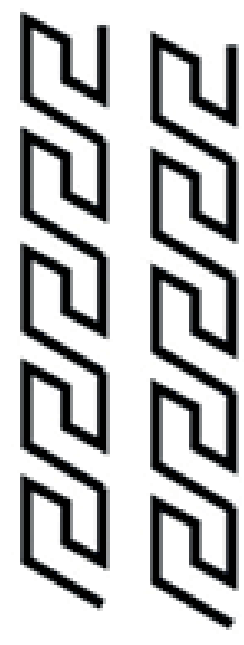

Kape hina, cola de caimán
Las asas de los morrales suelen presentar un patrón de cara de urdimbre que determina en sí mismo un tejido más compacto, resistente y adecuado a su función, lo mismo que una diversidad en los diseños como se observa en algunos ejemplos presentados en la Lámina 3.

Los diseños de la textilería cashinahuá presentan una dirección diagonal debido básicamente al empleo de la técnica sarga en donde el tipo de ligamento determina el alineamiento de los hilos, de trama y de urdimbre, por tanto de la visibilidad equilibrada de ambos elementos a lo largo del tejido. Sin embargo, el patrón de diseño de rombos, continuos o discontinuos, se encuentra organizado, por lo general, en dirección vertical a pesar del alineamiento diagonal del diseño.

En este sentido, podemos señalar dos patrones iconográficos significativos en la decoración aplicada al arte textil:

A. Patrón en rombo, donde se observan los rombos en una serie de combinaciones y secuencias, conectados o libres, rellenos o limpios, en secuencias alternas o continuas, dando forma a una gráfica compleja que vincula al universo natural (aves, felinos, ofidios), donde destaca el diseño ojo de lorito, txede bedu, circundado de caminos, sepi. La secuencia de los diseños más evidentes sigue una orientación vertical por lo general aunque también se observan desarrollos con tendencia diagonal. (Foto 29)

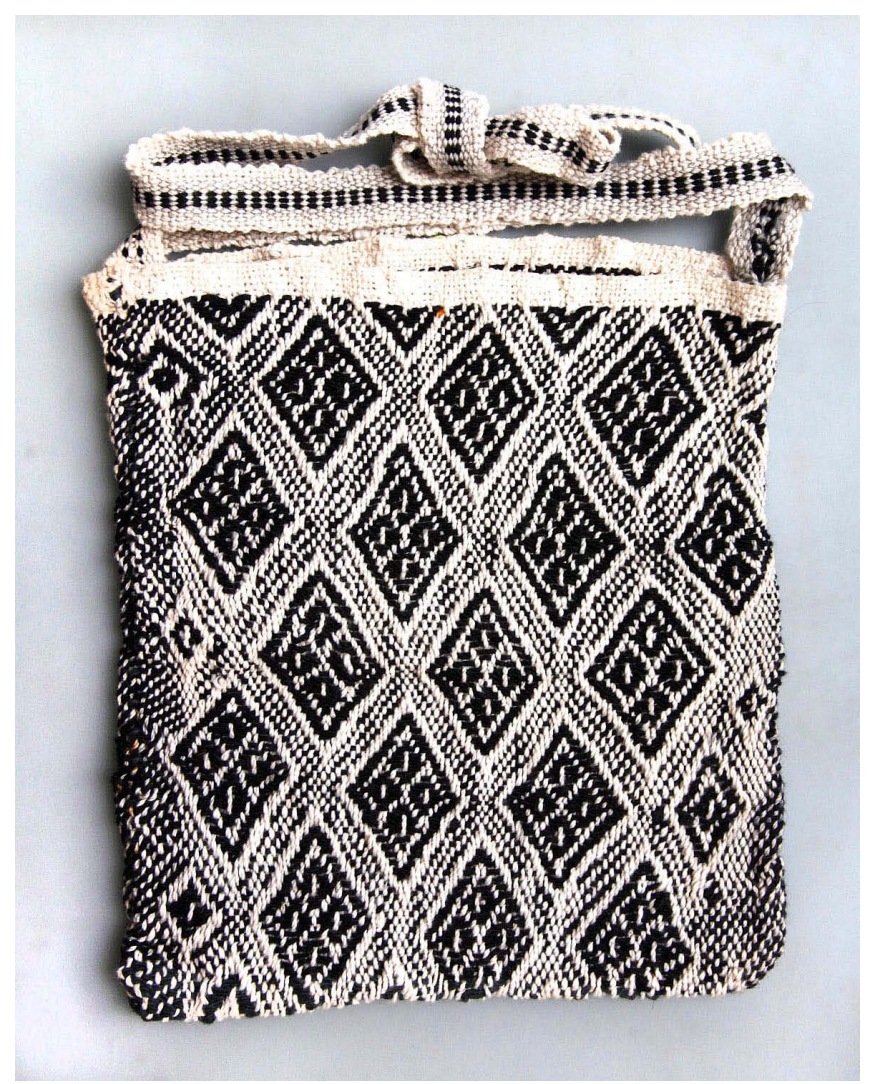

Foto 29 Morral. Patrón en rombo. Diseño inutai txede bedu, pisada de tigre con ojo de lorito. Río Kuranja 2019. Foto: B. Hare 


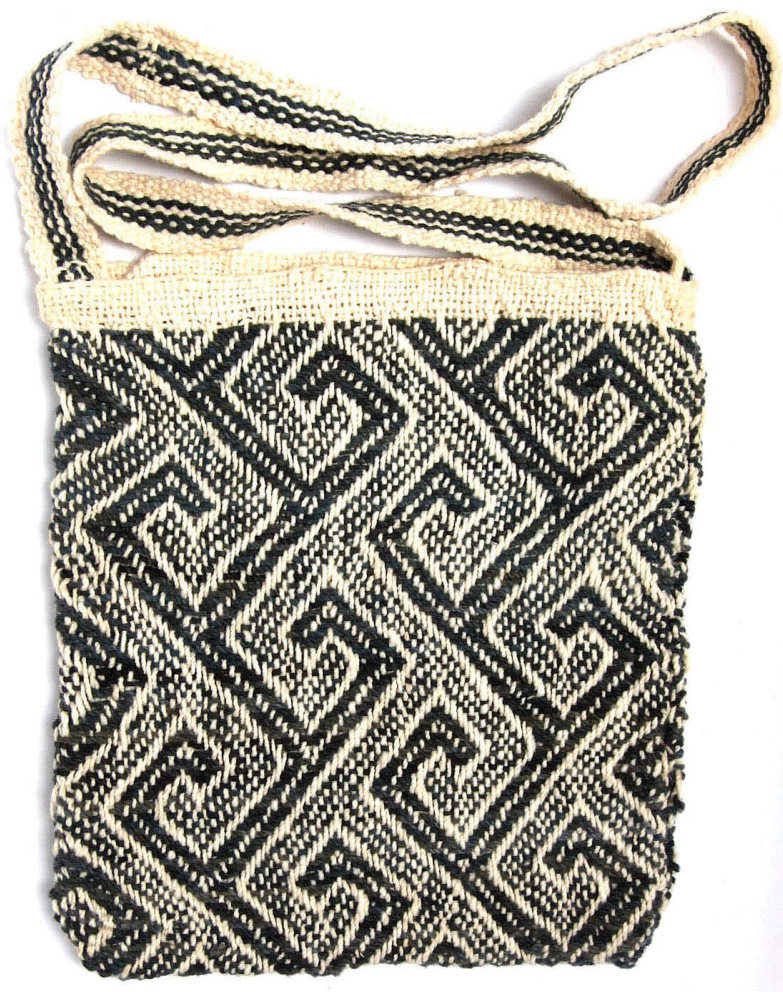

Foto 30 Morral. Patrón diagonal. Diseño mae muxa, uña de gato. Río Kuranja 2019. Foto: B. Hare

B. Patrón diagonal, asociado a un desarrollo diagonal de líneas continuas o quebradas, dobles o simples, que dibujan ganchos, en una suerte de 'interlocking', de rectángulos dobles abiertos en gancho o en la representación de formas vegetales paralelas, que delimitan espacios que igualmente refieren a caminos, sepi. La orientación de los diseños sigue una orientación diagonal. (Foto 30)

La relación de nomenclaturas asignadas a los diseños es vasta en tanto refiere a diversas modalidades de combinación de los elementos iconográficos y varía de acuerdo a la comunidad de origen y a la familia tejedora, pero siempre es posible encontrar el acuerdo entre las tejedoras después de un intercambio de opiniones frente al tejido.

Se puede concluir que el empleo repetido del nombre txede bedu (ojos de lorito) está haciendo referencia, además, a la figura del rombo, base de muchos diseños por lo que, por lo general, forma parte del apelativo compuesto. Entonces, inutai txede bedu podría entenderse como: pisada de tigre en rombo. También se entiende que dunu kate, buisan kate, dunu mapu, dunu mapu istutu o dunu hina dubu -espalda, cabeza y cola de culebra, mantona o boa- designan indistintamente a diseños diversos que aluden al peligroso ofidio que amenaza la vida de los pobladores, especialmente la de los cazadores, en un riesgo constante. Recordemos que los cashinahuá se dedican mayoritariamente a la caza, por lo que es posible que la aplicación de este diseño en los morrales de los cazadores pueda estar asociado a una suerte de conjuro o protección del portador.

El diseño sepi, camino, aparece frecuentemente alinderando o delimitando rombos, con mayor o menor ancho: bai besti (un camino), sepi baijaku (camino grande), sepi huku narunia (allí todos los caminos juntos), o complejidad: sepi natxu daniea (caminos apilados), sepi mepashkara (camino cortado o que se bifurca). Junto con los rombos, son las figuras que más importancia presentan para la conformación de diseños variados, además de ser especialmente significativas para la identidad huni kuin -visibilizadas en el mito de origen señalado antes- en los desplazamientos físicos por las trochas de la selva, o en los viajes del alma durante las sesiones de ayahuasca.

En la esfera ritual, una serie de ceremonias deben de garantizar el aprendizaje, la habilidad y una memoria acuciosa para recordar el variado repertorio de diseños en uso de la familia. Es frecuente que hasta la fecha se pinte a las niñas pequeñas en la cara algunos diseños con tinta de huito o de achiote, como xapu bexe, algodón amarrado, para transmitir de esta manera el conocimiento del arte del lenguaje de los diseños como parte del ritual de iniciación, mientras se cantan canciones alusivas a cada tipo de diseño. La maestra entrega a la niña, que puede o no ser su pariente, su sabiduría a través de los diseños pintados. En el mismo sentido y como parte de los ritos de pasaje que se observan en el ambito de las comunidades nativas, la tejedora maestra suele echar gotas de bawi (planta medicinal) en los ojos de las tejedoras más jóvenes o niñas, para aprender a dominar las técnicas, para no olvidar los diseños, y para saber resolver problemas con inteligencia y llegar a vivir con sabiduría. Esta ceremonia se puede repetir tantas veces como se desee, inclusive hasta la edad adulta, dando cuenta, así, de la importancia del embellecimiento de las personas y de los objetos para lo cual es fundamental su conservación como marcadores étnicos. (Foto 28) ${ }^{20}$

20. Durante mi estadía en las comunidades, mi interés y preguntas sobre técnicas y diseños textiles, propició el ofrecimiento de las gotas de bawi para facilitar mi aprendizaje del tejido. 


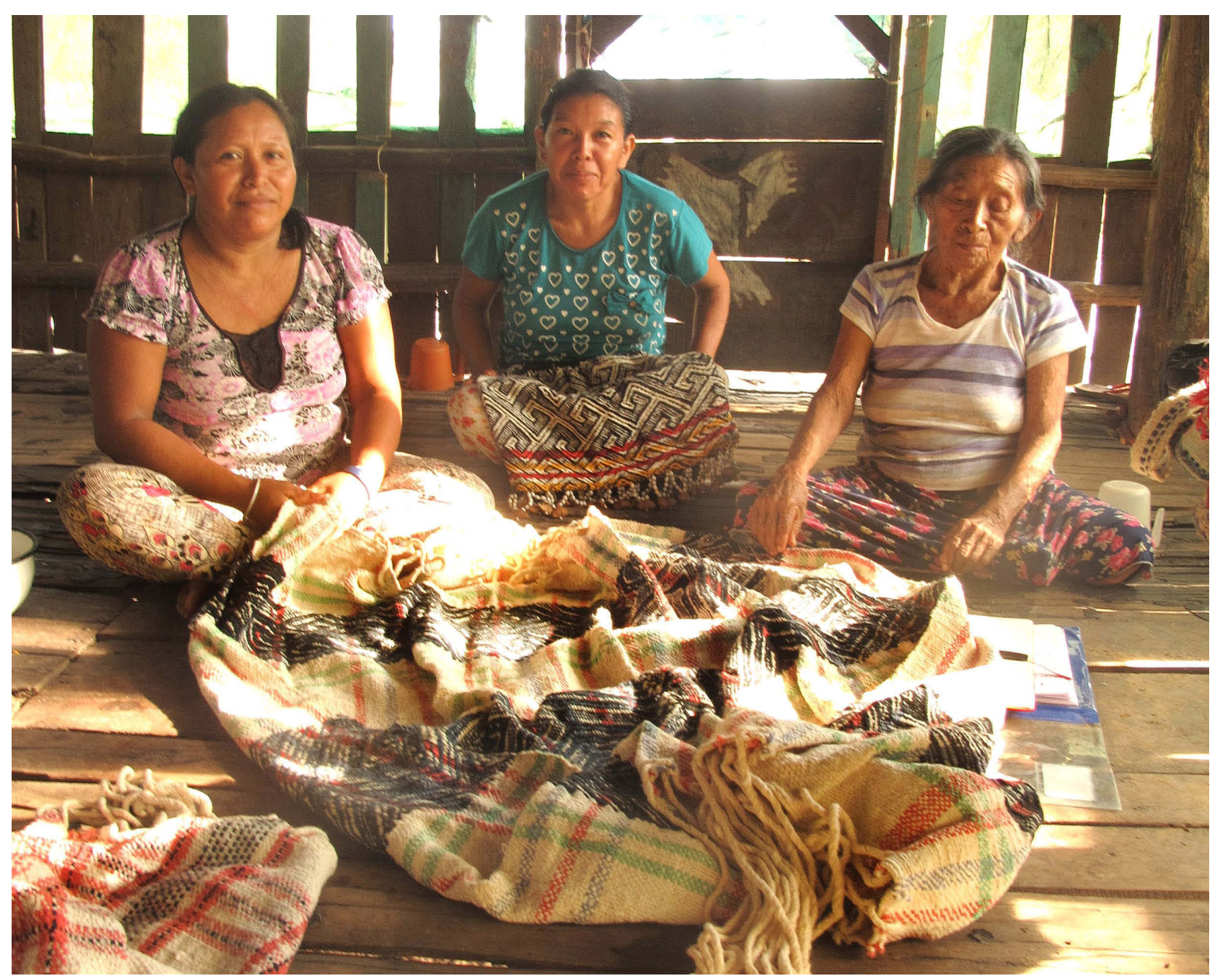

Foto 31 Izq. a der. Girma Bardales, María Nacimiento y Lucía Cumapa. CCNN San Martín 2019. Foto: M.E. del Solar.

El aprecio por un buen tejido considera por sobre todo que este sea parejo, en la tensión y calidad del hilo, nos dice gráficamente la maestra huni kuin Francisca Bardales, todo igualito bien derechito, otro no importa. Al respecto recoge Helen Tanner (1975:123) la admiración de las tejedoras por alguna de ellas mismas que pueda crear diseños complejos y, especialmente, por aquellos tejidos monócromos en donde el diseño es poco visible pero está presente en el objeto. ${ }^{21}$ La falta de simetría en el color y en el diseño, señala la misma fuente, no resta en absoluto a la calidad visual de los tejidos cashinahuá, es necesario rescatar el sentimiento de las propias tejedoras "lo bello no es completamente simétrico nunca”. ${ }^{22}$ (Foto 31)

\section{Agradecimientos}

Quiero agradecer muy especialmente a las maestras tejedoras entrevistadas en las comunidades nativas de Conta y San Martín, en el alto Purús, y de Nueva Luz y Colombiana, en el río Curanja, que compartieron de una manera tan generosa sus conocimientos conmigo, durante las temporadas de campo en los meses de julio y octubre-noviembre 2018 y enero-febrero 2019.

A los integrantes de las instituciones ProPurús, Parque Nacional Alto Purús y EcoPurús, quienes contribuyeron de muchas maneras a resolver mi estadía en la zona. También mi reconocimiento a Maribel Medina por su apoyo de

21. No fue posible conseguir ninguna muestra de este tipo a pesar que varias tejedoras manifestaron conocer ese estilo perfectamente. 22. Traducción personal. 
siempre y a Delia Aponte por su paciencia en la elaboración de los dibujos que acompañan este trabajo. A Isabelle Daillant por el préstamo de la imagen de la tejedora Mosetene.

Mi agradecimiento a Ann H. Peters y Lena Bjerregaard por haber asumido la responsabilidad editorial de este y todos los ensayos presentados en la Conferencia sobre Textiles Precolombinos en Bruselas 2019.

Por último, mi gratitud a Sophie Desrosiers por su inagotable disposición a compartir sus conocimientos y orientar mis interrogantes de la manera más generosa.

Y a Billy por apoyar y compartir mis sueños.

\section{Referencias citadas:}

AGÜERO, Carolina. 2015. Vestuario y sociedad andina. Desarrollo del Complejo Pica-Tarapacá (80o - 140o DC). QILLQA. Universidad Católica del Norte. Santiago: Ocho Libros Editores.

BARCLAY, Frederica. 2009. Análisis de situación de salud de la provincia de Purús, Ucayali. Serie Análisis de Situación de Salud y Tendencias. PERÚ/MINSA/DGE. (Informe versión digital)

BELAUNDE, Luisa E. 2009. Kené. Arte, ciencia y tradición en diseño. Lima: Instituto Nacional de Cultura.

DAWSON, Alice. 1975. Graphic Art and Design of the Cashinahua. En: The Cashinahua of Eastern Peru. (J. P. Dwyer ed.). Studies in Anthropology and Material Culture. Vol One. The Haffenreffer Museum of Anthropology. Brown University.

DESHAYES, P. y B. KEIFENHEIM. 2015. Pensar el otro. Entre los Huni Kuin de la Amazonía peruana. Lima: Instituto Francés de Estudios Andinos.

DESROSIERS, Sophie. 1992. Las técnicas del tejido ¿tienen un sentido? Una propuesta de lectura de los tejidos andinos. En: Revista andina. Año 10, No 1. Cusco: Centro Bartolomé de las Casas.
FERNÁNDEZ, Arabel. 2014. Fajas sara y pata de San Ignacio de Loyola, Patrimonio Cultural del Perú. En: Patrimonio del Perú. Humanidad Andina. C. Galvez y A. Rocchietti (Comp). Córdoba: Editorial Universitaria Villa María - Dirección Regional de Cultura, La Libertad.

2007. El anaku, la lliklla y las fajas sara y pata: supervivencias Inca en la comunidad de San Ignacio de Loyola, Sinsicap - Otuzco. En: La Trama y la Urdimbre. Textiles tradicionales del Perú. Lima: Universidad Ricardo Palma - Instituto Cultural Peruano Norteamericano.

KENSINGER, Kenneth M. 1998. Los cashinahua. En: Guia Etnográfica de la Alta Amazonía. Vol III. Santos Granero y Barclay (edit). Lima: Instituto Francés de Estudios Andinos.

1975. Studying the Cashinahua. En: The Cashinahua of Eastern Peru. (J. P. Dwyer ed.). Studies in Anthropology and Material Culture. Vol One. The Haffenreffer Museum of Anthropology. Brown University.

LAGROU, Els. 2009. Arte indígena no Brasil. Agencia, alteridade e relacao. Belo Horizonte: Editora C/ Arte.

MEISCH, Lynn A. 2007. Fajas sara: Supervivencia de una tradición textil inca en el norte del Perú. En: La Trama y la Urdimbre. Textiles tradicionales del Perú. Lima: Universidad Ricardo Palma - Instituto Cultural Peruano Norteamericano. 2006. Messages from the Past: An Unbroken Inca Weaving Tradition in Northern Peru. Textile Society of America Symposium Proceedings. Http://digitalcommons. unl.edu/tsaconf/345

RENARD-CASEVITZ, F.M. et al. 1988. Al Este de los Andes. Tomo I. Lima: Instituto Francés de Estudios Andinos.

TANNER, Helen. 1975. Cashinahua Weaving. En: The Cashinahua of Eastern Peru. (J.P. Dwyer ed.). Studies in Anthropology and Material Culture. Vol One. The Haffenreffer Museum of Anthropology. Brown University. 